\title{
Local Fiscal Policies and their Impact on the Number and Spatial Distribution of New Firms*
}

\author{
Nadine Riedel ${ }^{\dagger} \quad$ Martin Simmler ${ }^{\ddagger} \quad$ Christian Wittrock ${ }^{\S}$
}

January 24,2020

\begin{abstract}
We examine the effect of local business taxation and local public good and service (PIGS) provision on the number and spatial distribution of new firms. Testing ground is Germany and we rely on the universe of firm foundations between 1998 and 2006. Methodologically, we estimate fixed effects poisson models coupled with a control function approach. The results suggest that a 1\%-decrease in the business tax rate (the PIGS capital stock) raises (lowers) the number of new firms in the policychanging jurisdiction by $4.6 \%(0.8 \%)$. Business tax reductions, moreover, strongly reduce the number of firm foundations in neighboring municipalities, implying that the aggregate number of new firms remains unchanged; while PIGS provision, on average, does not impact the number of firms in adjacent jurisdictions, negative effects emerge for subsets of PIGS and firms.
\end{abstract}

JEL classification: D22, H4, H7, R30

Keywords: New Firms, Local Public Goods, Business Taxation, Spatial Effects

${ }^{*}$ We are grateful to Thushy Baskaran, Desiree Christofzik, Michael Devereux, Johannes Fleck, Eckhard Janeba, Wolfram Richter and participants of the IIPF Congress in Tokyo, the Congress of the German Economic Association in Vienna, the ZEW Public Finance Conference in Mannheim, the Spring Meeting for Young Economists in Halle, the RGS Jamboree in Dortmund, the Spatial Econometrics Association Conference in Roma and the 'Regional Economics and Local Political Economy' Workshop at the University of Siegen for helpful comments and suggestions. We gratefully acknowledge financial support from the German Research Foundation (Simmler: SI 2050/1-1 and Riedel RI 2491/2-1). Declarations of Interest: None.

${ }^{\dagger}$ Ruhr-University Bochum and CESifo Munich. E-mail: nadine.riedel@rub.de.

${ }^{\ddagger}$ Corresponding author: University of Oxford Centre for Business Taxation, Park End Street, OX1 1HP, Oxford, and DIW Berlin. E-mail: martin.simmler@sbs.ox.ac.uk.

${ }^{\S}$ Ruhr-University Bochum and TU Dortmund, Germany. E-mail: christian.wittrock@rub.de 


\section{INTRODUCTION}

Fostering the emergence of new businesses is a key concern for cities and municipalities around the globe (e.g. U.S. Chamber of Commerce Foundation (2016), Forbes (2017)). Whether and which policies are effective in channeling firm foundation decisions and help to attract inter-jurisdictionally mobile new businesses is largely indetermined though. The aim of this paper is to empirically identify the causal effect of fiscal policies, namely local business taxation and the provision of local public goods and services (PIGS), on firm foundation rates. Our testing ground is Germany, where local government spending - similar to other countries - significantly contributes to aggregate public spending and local governments, moreover, autonomously set local business tax rates. $^{1}$

To guide our empirical analysis, the paper starts out with a stylized theoretical two-jurisdiction-model. The model predicts that lower local business taxes raise the number of firm foundations in the policy-changing jurisdiction as more businesses enter the market and interjurisdictionally mobile new firms are attracted from the neighbouring locality. The latter effect implies that local business taxation gives rise to a beggar-thy-neighbour externality on the neighboring jurisdiction. Local PIGS provision is, moreover, predicted to have an ambiguous effect on the number of new firms in both, the PIGS-providing municipality and the neighboring jurisdiction. On the one hand, new PIGS spur firm entry in both jurisdiction (conditional on the assumption that PIGS raise firm profits in both localities). On the other hand, the relative attractiveness of communities changes: the quantitative gain in pre-tax

\footnotetext{
${ }^{1}$ Local government spending makes up around 20-30\% of overall government spending in developed countries (see OECD Statistics on Government Expenditure by Function). In Germany, local governments spent around 230 billion EURO in 2015 (see the website of the German Statistical Office). German localities moreover autonomously set the local business tax rate and the local property tax rate (with the latter being significantly less important in revenue-terms). In general, the level of sub-national tax autonomy significantly varies across countries (with sub-national governments in some countries having no tax instruments at hand at all).
} 
profits is plausibly larger for firms in the PIGS-increasing jurisdiction, which boosts its relative attractiveness and pulls in new firms that would have otherwise been founded in the neighboring jurisdiction. If the PIGS-increasing locality also taxes the additional PIGS-related profits at a higher business tax rate and firms within its borders, in consequence, obtain less PIGS-related after-tax benefits than firms in the neighoring jurisdiction, the effect may be reversed though, making the prediction on the overall link between PIGS and the number of new firms in the two jurisdictions ambiguous. $^{2}$

We test the predictions of the theoretical model using West Germany as a testing ground and drawing on panel information on the universe of firm foundations in West German municipalities linked to data on communities' local business tax choices and their local PIGS provision. PIGS are modeled based on spending information from municipality accounts, which is translated into PIGS capital stocks applying the perpetual inventory method. The data allows us to differentiate between detailed PIGS categories, including, e.g., spending for infrastructure, schools and recreational facilities. Methodologically, we rely on fixed effects Poisson models, which absorb time constant heterogeneity in firm foundation rates across German municipalities (see Guimarães et al. (2003) and Arauzo-Carod and Manjón-Antolín (2012)). ${ }^{3}$ Following our theoretical predictions, we, moreover, allow for both, own and cross-municipality effects of business tax choices and PIGS provision, with the latter being modeled by spatial lags of the regressors (see LeSage et al. 2009).

To address remaining endogeneity concerns, we apply a control function approach, where the PIGS capital stock and the local business tax rate are instru-

\footnotetext{
${ }^{2}$ Note that the model is included to provide guidance for our empirical analysis. It is positive in nature and we abstract from modeling optimal business tax and PIGS choices of jurisdictions.

${ }^{3}$ Guimarães et al. (2003) show that Poisson model estimates can be interpreted as estimates of a Conditional Logit model and are therefore suitable to model location decisions. Arauzo-Carod and Manjón-Antolín (2012), on top, show that the Poisson model can be used to determine the effects of geographically distributed regressors.
} 
mented using two excluded instruments. PIGS spending is instrumented exploiting variation in local business tax revenues, and eventually local public spending, generated by the 'Renewable Energy Sources Act' (RES Act) of 2000. This Act was initiated by the German federal government to promote energy production from renewable sources. Among others, the law created strong incentives for firms to construct wind power plants resulting in a substantial increase in the number of plants across Germany. As wind power plants are subject to local taxation, local business tax revenues of affected municipalities increased. Specifically, our instrumental variable strategy relies on differences in post-reform revenue and spending trends of communities with high levels of wind strength and unpopulated space relative to other localities - reflecting that wind power plants can only be built in areas with sufficient wind and sufficient free space.

Moreover, the municipalities' local business tax rate is instrumented exploiting variation in the so-called 'reference business tax' from the German municipal fiscal equalization scheme. Municipal fiscal equalization is organized through fiscal transfers from the state level to the municipality level if a municipality's fiscal capacity falls short from its fiscal needs. ${ }^{4}$ The latter is a conceded budget per resident, the former a measure for tax revenues at standardized tax rates (see e.g. Buettner and Holm-Hadulla (2008)). Local business tax revenues add to localities' fiscal capacity at such a standardized 'reference business tax rate'. This implies that, if the reference tax is larger than the municipality's actual tax rate, localities appear richer in the equalization scheme than they actually are and vice versa. Anecdotal evidence suggests that municipalities respond to changes in the position of their reference tax relative to the actual tax rate: If the reference tax is increased above the actual rate, local municipal councils also tend to adjust the business tax rate upwards. This is confirmed by empirical analysis, which shows that municipal business tax rates are ${ }^{4}$ If fiscal needs fall short from fiscal capacity, municipalities do not have to give up funds. 
anchored by the reference tax rate: Municipalities' local business taxes bunch at the reference tax from below, which is consistent with the notion that local officials aim to avoid appearing richer in the fiscal equalization scheme than they actually are. Following this line of argumentation, we instrument the local business tax choices with a dummy variable indicating if the reference tax rate in the fiscal equalization scheme is smaller or larger than a municipality's actual local business tax (where we use the actual rate in a pre-sample period to avoid obvious endogeneity concerns). ${ }^{5}$

Based on these instruments, the control function approach is implemented. In a first step, we run four sets of ordinary least squares regressions, where municipalities' PIGS provision, their local business tax and the spatial lags of these policy variables are regressed on the described instruments, a set of control variables and the spatial lag of all regressors. In a second step, the predicted residuals of these first stage regressions are included as regressors in the Poisson model for the number of new firm foundations to retrieve consistent estimates (see e.g. Wooldridge 2010). We, moreover, use bootstrapping to obtain valid standard errors. To correct for possible violations of the underlying Poisson distribution, the bootstrapped standard errors are, furthermore, clustered on the municipality level.

In line with our theoretical presumptions, our results suggest that local business taxes exert a large negative effect on the number of firm foundations in the policychanging jurisdiction. The estimated elasticity is -4.6 and thus in the range of prior estimates, see e.g. Becker et al. (2012) and Suárez Serrato and Zidar (2016). We, furthermore, show that business taxation exerts a strong fiscal externality on neighboring jurisdictions: Reducing the tax rate significantly lowers the number of firm foundations in other adjacent jurisdictions, implying that the aggregate number of new firms is unaffected by the tax-change. This suggests that business taxation largely serves as a beggar-thy-neighbor policy instrument.

\footnotetext{
${ }^{5}$ Time variation in the instrument hence relates to adjustments in the reference tax only.
} 
Moreover, we find evidence for a positive effect of PIGS on the number of firm foundations in the policy-changing jurisdictions. Quantitatively, a 1\%-increase in a municipality's PIGS stock raises the number of new firm foundations by $0.78 \%$ on average. For subsets of PIGS and subgroups of firms, the effect turns out to be larger in size: A 1\%-increase in PIGS targeted at families (e.g. public swimming, schooling, youth services) raises the number of new firm foundations in industries employing many workers who live with young children by $2.3 \%$. While PIGS provision, moreover, on average does not significantly impact on the number of new firm foundations in neighbouring jurisdictions, we find significant externalities for subsets of PIGS and subgroups of firms.

Our paper makes several contributions. Firstly, we add to a flourishing empirical literature on the effect of corporate taxes on firms' investment and location choices. While a negative link between federal corporate taxation and cross-country investment and location choices is well established (see e.g. Feld and Heckemeyer (2011) for a recent survey), evidence for the regional and local level tends to be scarce (see e.g. Brülhart et al. (2012), Becker et al. (2012), Suárez Serrato and Zidar (2016) and Giroud and Rauh (2017) for exceptions). Our analysis, moreover, differentiates from many prior papers by taking care of different potential endogeneity problems: Firstly, we combine a fixed effects framework with an instrumental variables approach to account for a correlation of localities' policy choices with unobserved municipality characteristics in the cross-sectional and longitudinal dimension; secondly, we allow for externalities of policy choices on neighboring jurisdictions. Testing for potential cross-jurisdictional effects has been largely ignored in the prior literature, despite the fact that allowing for such effects is conceptually and economically important: From a methodological point of view, estimates for tax and PIGS effects on firm activity in the policy-changing jurisdiction are biased if 
such externalities do exist and they are not accounted for in the empirical framework (as, technically speaking, the stable unit treatment value assumption, SUTVA, is violated and 'control' municipalities adjacent to treated municipalities are also affected by the policy change). ${ }^{6}$ On top, quantifying the size of fiscal externalities is economically important: If tax reductions or PIGS increases raise the number of new firm foundations in the policy-changing country but lead to a 1:1-decline in the number of firm foundations in neighboring jurisdictions - as suggested for business taxes and for some PIGS dimensions in our analysis -, the policy instruments fail to spur aggregate business foundations and serve as beggar-thy-neighbor instruments instead. The identified cross-border policy effects, moreover, support local public sector theories where fiscal interactions between jurisdictions root in firm mobility across borders and the responsiveness of firms' spatial location choices to changes in local policy instruments. ${ }^{7}$

Furthermore, we are, to the best of our knowledge, the first to provide a comprehensive analysis of the causal link between local PIGS and firm activity. While a number of much-noted recent papers assesses whether economic activity is affected by large supra-regional infrastructure projects, like the construction of dams, motorways and railroads (see e.g. Holl (2004), Duflo and Pande (2007), Donaldson (2018) and Moeller and Zierer (2018)) and by place-based policies (see e.g. Neumark and Simpson (2015)), these policy interventions differ from local public good provision in two ways: Firstly, they are planned and financed by the federal level, implying that fiscal externalities (at the sub-national level) are ruled out by definition.

\footnotetext{
${ }^{6}$ Note that instrumental variable strategies do not solve this problems if instruments are correlated across space (as they plausibly often are, see below).

${ }^{7}$ Note that our findings do not allow us to draw conclusions regarding the optimal level of fiscal decentralization. While we show that local policy instruments exert an externality on neighboring jurisdictions, the welfare implications of local policy choices also depend on the sign and size of spatial fiscal policy interactions (where empirical evidence is mixed, see e.g. Devereux et al. (2008), Baskaran and Hessami (2014), Parchet (2019)). For recent contributions to and reviews of the literature on tax competition and tax coordination in federations, see e.g. Siggelkow (2018), Hopp and Kriebel (2019) and Keen and Konrad (2013).
} 
Secondly, while most supra-regional infrastructure projects directly increase firm productivity, many local PIGS, like public swimming, parks, schooling and youth services, are first and foremost targeted at households. Our paper stresses that the latter may, nevertheless, spur local firm foundations as entrepreneurs might obtain benefits from PIGS provision and may, for that reason, relocate to PIGS-providing localities or because a firm's workers might become more productive or may be willing to live and work in a locality or region for a lower wage. ${ }^{8}$ As described above, our empirical results confirm a link between local PIGS and firm foundation rates.

The rest of the article is structured as follows. In Section II, we present a stylized theoretical model to guide our empirical approach. Section III describes the institutional background of the empirical analysis and the data used. The estimation strategy and empirical results are presented in Section IV. Section V concludes.

\section{TheOretical CONSIDERATions}

Before turning to the empirical analysis, we develop a simple theoretical model to guide our empirical approach. Consider a world with two communities $j=1,2$, which are located at the end points of the unit interval. We denote the location of municipality $j$ by $g_{j}$ and assume $g_{1}=0$ and $g_{2}=1$. There is a mass 1 of firms that are characterized by their location preferences. The bliss location point of firm $k$ is denoted by $x^{k}$. We assume that bliss points are uniformly distributed across the unit interval. Firm owners decide in which locality to locate by maximizing

\footnotetext{
${ }^{8}$ Surveys with business owners indeed suggest that the quality of local PIGS matters for location decisions (see Section II). Note, moreover, that the literature paid some attention to the consequences of local schooling expenditures on households by studying the effect on student outcomes (see e.g. Jackson et al. (2016)) or property prices (see e.g. Ries and Somerville (2010)). Potential effects on firm behaviour have so far, however, been largely ignored though. One exception is the study by Gabe and Bell (2004). They investigate the impact of educational spending on firm entry on the municipality level in Maine between 1993 and 1995. They find for some spending categories (e.g. schools that offer education to the twelfth grade) a positive and for other (e.g. school transport) a negative impact. Due to the short time period, the effects are, however, identified using variation over time as well as variation between municipalities within a county.
} 
their profit after mobility costs which relate to moving away from the bliss location. Mobility costs from locating at municipality $j$ are given by $m\left(\left|x^{k}-g_{j}\right|\right)=m\left(\delta_{j}^{k}\right)$, where $\delta_{j}^{k}$ denotes the distance between firm $k$ 's location bliss point and municipality $j$ and $m^{\prime}(\cdot)>0.9$

Municipalities control two policy instruments that affect firm profits: the corporate income tax rate $t_{j}$ and the level of public input goods and services (PIGS) $c_{j}$. In the following, we will assume that PIGS raise firm profits. The benefit that a firm located in municipality $j$ receives from PIGS provision is denoted by $B_{j}\left(c_{1}, c_{2}\right)$. Assumptions. The function $B_{j}\left(c_{1}, c_{2}\right)$ satisfies:
1. $\frac{\partial B_{j}}{\partial c_{j}}>0$.
2. $\frac{\partial B_{i}}{\partial c_{j}}>0, i \neq j$.

3. For any given PIGS level in municipality $i, \bar{c}_{i}: \frac{\partial B_{j}\left(c_{j}, \bar{c}_{i}\right)}{\partial c_{j}}>\frac{\partial B_{i}\left(c_{j}, \bar{c}_{i}\right)}{\partial c_{j}}$.

The first assumption states that firms benefit from higher PIGS provision in their host municipality. This positive effect on corporate profitability may firstly relate to PIGS provision that directly increases firm productivity, e.g. publicly funded research and development centers. Alternatively, PIGS may help to lower input costs; public infrastructure provision may e.g. lower transportation costs or PIGS directed towards households may imply that employees are willing to work for lower wages to enjoy the benefits from regional amenities (e.g. recreation facilities, like parks or public swimming). ${ }^{10}$ Survey evidence confirms that business owners consider the quality of local PIGS when making location decisions (see, e.g., Sonoran

\footnotetext{
${ }^{9}$ Note that we hence assume that firms may not be able to locate in a community at the location of their bliss point. This may reflect zoning restrictions or that firm owners have a preference to locate their business in their home residential community, which may, however, for business reasons (e.g. market access) not be a suitable business location.

${ }^{10} B_{j}$ may also be interpreted as the PIGS-related utility of an enterpreneur when he locates in community $j$. In this case, a link between local PIGS and $B_{j}$ may not only be established via changes in firm profits but might also emerge because the enterpreneur obtains direct benefits from PIGS provision (like public swimming or parks) when locating in jurisdiction $j$.
} 
Institute (2015), UK Government - Department for Business, Energy and Industrial Strategy (2019)). Prior empirical findings, moreover, suggest that PIGS impact individuals' location choices and thus affect labor supply, wage rates and firm profits (see, e.g., Albouy and Lue (2015) and Buettner and Janeba (2016)). The second assumption states that increases in PIGS also have a positive effect on firm profits in the neighbouring municipality. Roads may e.g. also reduce transport costs for firms located in adjacent localities (if they, for example, reduce the travel time to the next highway) or may benefit workers in neighbouring jurisdictions who are then willing to work for lower wages. Finally, the third assumption states that the incremental PIGS benefits to businesses decrease with the distance to the PIGS providing community, i.e. firms located in community $i \neq j$ benefit less from an increase in $c_{j}$ than firms located in locality $j$.

The profit net of mobility cost and taxes of firm $k$ when it locates in municipality $j$ is then given by

$$
\pi_{j}^{k}=\left(1-t_{j}\right)\left(V+B_{j}\left(c_{1}, c_{2}\right)\right)-m\left(\delta_{j}^{k}\right)
$$

where $V$ is a location independent component of profits; we, moreover, assume that mobility cost are not tax deductible. ${ }^{11}$ Each firm has to make two decisions: first, it has to decide whether to enter the market, and second, conditional on entry, it has to decide in which community to locate. We begin the analysis with the second decision.

Location Choice. A firm with bliss point $x$ locates in municipality 1 if

$$
\begin{aligned}
& \Delta(x) \equiv \pi_{1}^{k}-\pi_{2}^{k}= \\
& \left(t_{2}-t_{1}\right) V+\left(\left(1-t_{1}\right) B_{1}\left(c_{1}, c_{2}\right)-\left(1-t_{2}\right) B_{2}\left(c_{1}, c_{2}\right)\right)+m(1-x)-m(x) \geq 0
\end{aligned}
$$

\footnotetext{
${ }^{11}$ See a prior version for a model with partially tax deductible mobility cost (Riedel et al. (2018)).
} 
To rule out cases where all firms locate in one municipality, we assume that $m(1)$ is sufficiently high. The optimal location decision rule and and how it depends on municipalities' policy choices is stated in the following two lemmas.

Lemma 1. There exists a unique cutoff value $\bar{x}$ such that firms with location bliss point $x^{k} \leq \bar{x}$ locate at municipality 1 and firms with location bliss point $x^{k}>\bar{x}$ locate at municipality 2.

Proof. See Appendix A.

Lemma 2. $\bar{x}$ is a function of $t_{1}, t_{2}, c_{1}$ and $c_{2}$ where

1. $\bar{x}$ decreases in $t_{1}$ and increases in $t_{2}$.

2. The impact of higher PIGS provision on $\bar{x}$ is ambiguous.

- $\bar{x}$ shifts to the right in response to an increase in $c_{1}$ if

$$
\left(1-t_{1}\right) \frac{\partial B_{1}}{\partial c_{1}}>\left(1-t_{2}\right) \frac{\partial B_{2}}{\partial c_{1}},
$$

and shifts to the left otherwise.

- Analogously, $\bar{x}$ shifts to the right in response to an increase in $c_{2}$ if

$$
\left(1-t_{1}\right) \frac{\partial B_{1}}{\partial c_{2}}>\left(1-t_{2}\right) \frac{\partial B_{2}}{\partial c_{2}}
$$

and shifts to the left otherwise.

Proof. See Appendix A.

Lemma 2.1, intuitively, states that a municipality becomes a less attractive firm location when its business tax rate increases. Lemma 2.2 shows that PIGS provision also affects the relative attractiveness of communities as a firm location, with the sign depending on the incremental net-of-tax-benefit of higher PIGS provision for firms in 
the two jurisdictions. As stated in the assumptions, the incremental pre-tax benefit of PIGS is assumed to be larger for firms in the PIGS-providing jurisdiction. This, however, does not necessarily imply that the PIGS-increasing jurisdiction becomes the more attractive place for firm location: If its business tax rate is sufficiently larger than the tax in the other jurisdiction, the higher marginal pre-tax PIGSbenefits may be eaten up by the higher tax levy. Intuitively, this becomes more likely if the difference between the pre-tax benefits from PIGS earned by firms in the two jurisdictions is small (i.e. when the benefits of PIGS provision fade out slowly with distance).

Entry. We now turn to firms' decisions to enter into the market or not. To endogenize the number of firms that enter, we assume that the location independent component of firm profits $V$ is a random variable with distribution function $F(v)$ and strictly positive density $f(v) .{ }^{12}$ A firm with bliss point $x \leq \bar{x}$ enters into municipality 1 only if

$$
\begin{array}{r}
\left(1-t_{1}\right)\left(V+B_{1}\left(c_{1}, c_{2}\right)\right)-m(x) \geq 0 \Longleftrightarrow \\
V \geq \frac{1}{1-t_{1}} m(x)-B_{1}\left(c_{1}, c_{2}\right) \equiv \bar{v}_{1}\left(x, t_{1}, c_{1}, c_{2}\right) .
\end{array}
$$

It can easily be checked that $\bar{v}_{1}$ increases in $t_{1}$ implying that under a higher corporate tax rate only firms with higher draws for $V$ will find it optimal to enter. This reflects that higher corporate tax rates reduce firm profits and thus incentives to enter. Analogously, $\bar{v}_{1}$ decreases in both $c_{1}$ and $c_{2}$ implying that PIGS provision in either municipality spurs entry.

The total mass of firms locating at municipality $1, M_{1}$, can be calculated as

$$
M_{1}=\int_{0}^{\bar{x}} \operatorname{prob}\left(V \geq \bar{v}_{1}\left(x, t_{1}, c_{1}, c_{2}\right)\right) d x=\int_{0}^{\bar{x}}\left[1-F\left(\bar{v}_{1}\left(x, t_{1}, c_{1}, c_{2}\right)\right)\right] d x .
$$

\footnotetext{
${ }^{12}$ Notice that we assume that the distribution of $V$ is independent from the location bliss point.
} 
Analogously, a firm with location bliss point $x>\bar{x}$ enters into municipality 2 if

$$
\begin{array}{r}
\left(1-t_{2}\right)\left(V+B_{2}\left(c_{1}, c_{2}\right)\right)-m(1-x) \geq 0 \Longleftrightarrow \\
V \geq \frac{1}{1-t_{2}} m(1-x)-B_{2}\left(c_{1}, c_{2}\right) \equiv \bar{v}_{2}\left(x, t_{2}, c_{1}, c_{2}\right),
\end{array}
$$

yielding a total mass of entering firms in municipality 2

$$
M_{2}=\int_{\bar{x}}^{1} \operatorname{prob}\left(V \geq \bar{v}_{2}\left(x, t_{2}, c_{1}, c_{2}\right)\right) d x=\int_{\bar{x}}^{1}\left[1-F\left(\bar{v}_{2}\left(x, t_{2}, c_{1}, c_{2}\right)\right)\right] d x .
$$

It is now straight forward to assess how changes in the corporate income tax rate and PIGS provision affect the number of firms in both municipalities.

Consider first an increase in $t_{2}$. Notice that a change in $t_{2}$ affects two cutoff values. First, the location cutoff $\bar{x}$ below which firms locate in municipality 1 and, second, the cutoff value for the location independent components of firm profits $\bar{v}_{1}\left(x, t_{1}, c_{1}, c_{2}\right)$ and $\bar{v}_{2}\left(x, t_{2}, c_{1}, c_{2}\right)$, above which firms find it optimal to enter. By Lemma 2, the increase in $t_{2}$ shifts $\bar{x}$ to the right. Moreover, a higher value of $t_{2}$ increases $\bar{v}_{2}$ (see above) and thus reduces incentives to enter in municipality 2 , while it leaves profits of firms locating in municipality 1 and thus $\bar{v}_{1}$ unaffected. Hence, higher tax rates in municipality 2 unambiguously increase (decrease) the mass of firms in municipality 1 (2). Formally, applying Leibnitz' Rule yields

$$
\begin{aligned}
\frac{\partial M_{1}}{\partial t_{2}} & =\frac{\partial}{\partial t_{2}} \int_{0}^{\bar{x}\left(t_{2}\right)}\left[1-F\left(\bar{v}_{1}\left(x, t_{1}, c_{1}, c_{2}\right)\right)\right] d x \\
& =\int_{0}^{\bar{x}\left(t_{2}\right)} \frac{\partial}{\partial t_{2}}\left[1-F\left(\bar{v}_{1}\left(x, t_{1}, c_{1}, c_{2}\right)\right)\right] d x+\left[1-F\left(\bar{v}_{1}\left(\bar{x}, t_{1}, c_{1}, c_{2}\right)\right)\right] \frac{\partial \bar{x}}{\partial t_{2}} \\
& =-\int_{0}^{\bar{x}} f\left(\bar{v}_{1}\right) \underbrace{\frac{\partial \bar{v}_{1}}{\partial t_{2}}}_{=0} d x+\left[1-F\left(\bar{v}_{1}\right)\right] \frac{\partial \bar{x}}{\partial t_{2}} \\
& =\left[1-F\left(\bar{v}_{1}\right)\right] \frac{\partial \bar{x}}{\partial t_{2}}>0,
\end{aligned}
$$


where we suppressed the dependence of the functions $\bar{v}_{1}$ and $\bar{x}$ on their arguments for notational simplicity. Analogously,

$$
\begin{aligned}
\frac{\partial M_{2}}{\partial t_{2}} & =\frac{\partial}{\partial t_{2}} \int_{\bar{x}\left(t_{2}\right)}^{1}\left[1-F\left(\bar{v}_{2}\left(x, t_{2}, c_{1}, c_{2}\right)\right)\right] d x \\
& =-\int_{\bar{x}}^{1} f\left(\bar{v}_{2}\right) \frac{\partial \bar{v}_{2}}{\partial t_{2}} d x-\left[1-F\left(\bar{v}_{2}\right)\right] \frac{\partial \bar{x}}{\partial t_{2}}<0 .
\end{aligned}
$$

The analysis for changes in $t_{1}$ is analogous.

Next, we analyse how PIGS provision in municipality 2 affects the mass of firms in both municipalities. Notice again that a change in $c_{2}$ affects both the location cutoff $\bar{x}$ and the entry cutoffs $\bar{v}_{1}\left(x, t_{1}, c_{1}, c_{2}\right)$ and $\bar{v}_{2}\left(x, t_{2}, c_{1}, c_{2}\right)$. The change in the mass of firms at municipality 1 and 2 can be calculated by differentiating $M_{1}$ and $M_{2}$. Applying Leibnitz' Rule yields

$$
\begin{aligned}
\frac{\partial M_{1}}{\partial c_{2}} & =\frac{\partial}{\partial c_{2}} \int_{0}^{\bar{x}\left(c_{2}\right)}\left[1-F\left(\bar{v}_{1}\left(x, t_{1}, c_{1}, c_{2}\right)\right)\right] d x \\
& =\int_{0}^{\bar{x}\left(c_{2}\right)} \frac{\partial}{\partial c_{2}}\left[1-F\left(\bar{v}_{1}\left(x, t_{1}, c_{1}, c_{2}\right)\right)\right] d x+\left[1-F\left(\bar{v}_{1}\left(\bar{x}, t_{1}, c_{1}, c_{2}\right)\right)\right] \frac{\partial \bar{x}}{\partial c_{2}} \\
& =-\int_{0}^{\bar{x}} f\left(\bar{v}_{1}\right) \frac{\partial \bar{v}_{1}}{\partial c_{2}} d x+\left[1-F\left(\bar{v}_{1}\right)\right] \frac{\partial \bar{x}}{\partial c_{2}} .
\end{aligned}
$$

The analogous expression for municipality 2 is

$$
\begin{aligned}
\frac{\partial M_{2}}{\partial c_{2}} & =\frac{\partial}{\partial c_{2}} \int_{\bar{x}\left(c_{2}\right)}^{1}\left[1-F\left(\bar{v}_{2}\left(x, t_{2}, c_{1}, c_{2}\right)\right)\right] d x \\
& =-\int_{\bar{x}}^{1} f\left(\bar{v}_{2}\right) \frac{\partial \bar{v}_{2}}{\partial c_{2}} d x-\left[1-F\left(\bar{v}_{2}\right)\right] \frac{\partial \bar{x}}{\partial c_{2}}
\end{aligned}
$$

The change in the mass of firms depends on two terms: the first term reflects entry incentives, while the second term reflects location choices. The first terms are both positive ${ }^{13}$ reflecting that higher PIGS provision increases profits in both ${ }^{13} \mathrm{As} \partial \bar{v}_{1} / \partial c_{2}$ and $\partial \bar{v}_{2} / \partial c_{2}$, are both negative, see above. 
municipalities, thus spurring entry. The sign of the second term is ambiguous in both expressions. By Lemma 2,

$$
\frac{\partial \bar{x}}{\partial c_{2}}<0 \quad \text { if } \quad\left(1-t_{2}\right) \frac{\partial B_{2}}{\partial c_{2}}>\left(1-t_{1}\right) \frac{\partial B_{1}}{\partial c_{2}}
$$

In this case, higher PIGS provision in municipality 2 makes municipality 2 the more attractive location leading to an increase in $M_{2}$. In municipality 1 , however, the positive entry effect is opposed by the higher propensity of firms to locate in municipality 2 yielding an ambiguous overall effect for the change in $M_{1}$. Conversely, if $\partial \bar{x} / \partial c_{2}>0$, municipality 1 gains firms while the effect on municipality 2 is ambiguous. The analysis is analogous for changes in $c_{1}$.

Summarizing, we arrive at two predictions: Firstly, lower corporate tax rates are predicted to increase the mass of new firms in the policy-changing jurisdiction and decrease the mass of new firms in the other municipality. Secondly, the effect of PIGS on firm entry is ambiguous for both municipalities. ${ }^{14}$

\section{InstitutionAl BACKGROUND AND DATA}

In the following, these predictions will be brought to the data. The testing ground are firm foundations in West German municipalities. This section describes the institutional background and the data set used for the empirical analysis.

\footnotetext{
${ }^{14}$ Note that our stylized theoretical model, in line with our empirical setup below and the existing literature, makes ceteris paribus predictions on how firm choices depend on local business tax rates and PIGS provision respectively, conditional on the choice of the other policy instrument. As our empirical analysis is concerned with the impact of public policies on firm behaviour, we refrain from analysing governments' optimal policy choices in our theoretical framework.
} 


\section{A. Institutional Background}

Municipalities in Germany are the lowest institutional legislative jurisdiction. They have self elected legislative governments and have the right to solve any local matters autonomously (Article 28 of the German constitution). Localities generate income from two main sources. First, a fraction of the personal income tax and the value added tax revenue administered at the federal and state level are distributed to German municipalities based on fiscal rules.

Second, localities autonomously set the local business tax rate, which is levied on business earnings of incorporated and non-incorporated firms located within a community's borders. The definition of the business tax base is determined by federal law and is thus homogenous across municipalities. The tax significantly contributes to the tax burden on businesses in Germany and is also the most important revenue instrument at German communities' own discretion. ${ }^{15}$ The business tax multiplier set by German municipalities is measured in business tax points and is multiplied by a base rate ('Messzahl') chosen at the federal level when calculating a firm's tax levy. In our sample period, a proportional base rate of $5 \%$ applied for corporations (and for non-incorporated firms on income above EUR 48,000 (Par. 11 Local Business Tax Act)). ${ }^{16}$ Note, moreover, that the majority of local tax revenues remains with the locality. Only a minor fraction is redistributed by fiscal equalization schemes. German municipalities also provide various local public goods and services, e.g. related to the construction and maintenance of roads, sewerage, kindergartens and primary schools. Furthermore, municipalities have to provide social benefits to the unemployed and social welfare recipients. Additionally, public goods and services re-

\footnotetext{
${ }^{15}$ Communities also levy a local property tax which is, however, a significantly less important revenue source than the local business tax.

16 As will be stated below, the average local business tax multiplier set by localities within our sample is 339 business tax points. Multiplied with a base rate of $5 \%$, this translates in a tax levy of around $17 \%$ (with this calculation ignoring that firms' effective tax burdens are also determined by the deductibility of local business tax payments from the local business tax base).
} 
lated to culture and sport facilities, tourism, and public transport may be provided. Note that while some expenditures are mandatory, including administration, social security and financing liabilities, others are optional, including e.g. spending for theaters, youth centers, the promotion of science, health care, sport and recreation facilities.

\section{B. Data}

As described above, our empirical analysis assesses the effect of business taxes and local PIGS on the number of firm foundations in Germany. The analysis is based on three different data sets. First, we use data on the number of firm foundations in German municipalities, specifically the total number of newly registered corporate enterprises, partnerships and self employed people (full time and with at least 1 employee) per municipality drawn from the Gewerbeanzeigenstatistik of the German State Statistical Offices. Note that the registration of a new branch will also be counted as a new foundation and that, by law, owners are required to register any new business.

Second, we use information on the local business tax rate set by German communities (provided by Statistic Lokal) and their local public good and service provision (PIGS). The PIGS information stems from disaggregated accounting data of German municipalities provided in the Jahresrechnungsstatistik of the State Statistical Offices. The data comprises information for different spending categories. In the analysis to come, we will focus on autonomous spending by German communities, i.e. disregard community spending that is mandatory by German law (e.g. spending for housing support paid to welfare recipients) or organized through higher administrative units like counties. This leaves us with administrative and capital expenditures by German municipalities for (a) public security, (b) schools, (c) public education 
and culture, (d) child and youth care, (e) health, recreation and sports, (f) public transportation and parking, (g) construction and housing, (h) municipality streets as well as $(\mathrm{j})$ economic promotion. ${ }^{17}$

We apply the perpetual inventory method to generate values for the actual PIGS stock of each municipality (in different PIGS categories). To do so, we calculate the initial stock value $K_{0}$ using expenditure information for the pre-sample period (1992 to 1997) with

$$
K_{0}=\frac{\overline{E X P}}{g_{g d p}+\frac{1}{T}} .
$$

where $\overline{E X P}$ stands for the mean PIGS expenditures between 1992 to 1997, $g_{g d p}$ for the GDP growth rate and $T$ for the average operating life. Note that we will assume a GDP growth rate of $2 \%$. We assume linear depreciation of the initial capital stock. Depreciation rates are calculated using publicly available information about operating lifes of assets in the different spending categories. Investment is represented by capital expenditures for a specific PIGS category in every year. Additionally, we add administration expenditures in every year, but assume $100 \%$ depreciation of the latter within one year. Hence, the PIGS capital stock $C_{\ell, i, t}$ of asset $\ell$ in municipality $i$ at time $t$ reads

$$
C_{\ell, i, t}=\sum_{k=0}^{T_{\ell}} E X P_{\ell, i, t-\ell}\left(1-\frac{k}{T_{\ell}}\right)+A D M_{\ell, i, t}
$$

\footnotetext{
${ }^{17}$ Public security comprises spending for police, fire fighters, public order and ambulance services; spending for schools comprises spending for school buildings and facilities for primary and secondary schools located in the community; spending for culture and public education comprises spending for science and research, museums, theatres and concert halls, public libraries, regional traditions and monuments; spending for child and youth care comprises spending for public youth services and family-related services; spending for health, sport and recreation comprises spending for sport facilities and sport support, public swimming, gardens and parks; spending for public transportation and parking comprises spending for street lightning and cleaning, the construction and maintenance of parking spaces as well as public transport services; spending for construction and housing comprises spending for public building authorities, urban planning and construction as well as housing promotion; spending for streets comprises spending for municipality streets only - the construction and maintenance of streets that cross municipality borders like highways are the responsibility of federal or state governments.
} 
with $E X P_{\ell, i, t}$ depicting capital expenditures, $A D M_{\ell, i, t}$ administration expenditures and $T_{\ell}$ the average operating life of asset category $\ell$. We assume that the expenditures in 1992 (the starting year of our data) are equal to the capital expenditures plus the initial capital stock $K_{0}$. Hence, expenditures before 1992 are assumed to be equal to 0 . Note that the capital stock in equation (2) is constructed for the different PIGS categories described above and then summed up to a total PIGS capital stock per municipality.

Third, we add socio-economic municipality characteristics to our data. The latter include information on municipal population in 1000 , the unemployment rate, the share of low, medium and high skilled workers and the number of students (per 1000 inhabitants) and doctors (per 100,000 inhabitants). ${ }^{18}$

The sample period of our empiricial analysis covers the years from 1998 to 2006 since the firm foundation rates are only available from 1998 onwards. Further, we restrict the analysis to years prior to 2006 as information on PIGS spending from German municipality accounts fails to be available in consistent format before and after 2007 due to a major change in the German municipality accounting system in 2007. Since information on PIGS spending is, available, from 1992 onwards, we use 1992 to 1997 to construct the initial PIGS stocks. To avoid that few, very large jurisdictions are driving our results, we exclude municipalities with a population greater than 300,000 from the main analysis (corresponding to the upper 0.25 th percentile of the population distribution), which leaves us with 8,130 municipalities in the baseline estimation sample.

Descriptive statistics for our estimation sample are presented in Figure (1) and in Table (1). Figure (1) depicts our sample municipalities' average PIGS stock per PIGS category relative the total PIGS capital stock in the year 2006. The figure

\footnotetext{
${ }^{18}$ Note that information on the share of workers, the number of students and the number of doctors is available at the county level only.
} 
indicates that the largest fraction of the PIGS stock of German municipalities is associated with schools, followed by child and youth care as well as streets, public transport and parking and recreational facilities. PIGS related to culture, public education, economic promotion and social security are, in quantitative terms, less important.

Figure 1: Average Share of PIGS Stocks in 2006

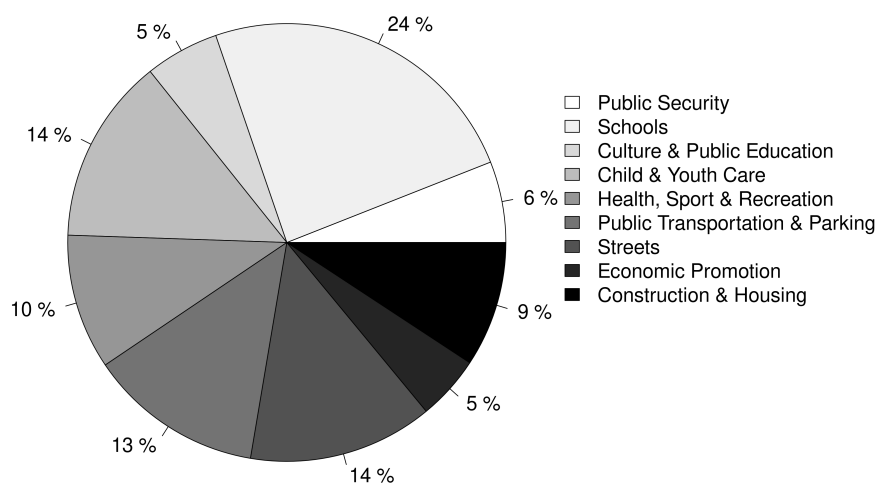

Table (1) moreover shows that the average municipality in our data has 6,700 inhabitants. The average (median) municipality observes 11 (2) firm foundations per year. The underlying distribution is thus - as shown in Figure (2) - right-skewed. The average PIGS capital stock is 30.4 Million Euro and the average PIGS stock per inhabitant 5139 Euros, with significant variation across municipalities though. The average local business tax multiplier amounts to 339 business tax points, which multiplied with a base rate ('Messzahl') of $5 \%$ (see above) translates into a local business tax rate of around 17\% (see also Footnote 16). 
Table 1: Descriptive Statistics

\begin{tabular}{lccccc}
\hline & Mean & Std. Dev. & Pctl(25) & Pct(50) & Pctl(75) \\
\hline \# of Firm Foundations & 10.65 & 32.32 & 0.00 & 2.00 & 8.00 \\
Population in 1,000 & 6.71 & 16.79 & 0.82 & 1.90 & 6.02 \\
Unemployment Rate in \% & 5.35 & 1.82 & 4.00 & 5.00 & 6.40 \\
Share of Low Skilled Workers in \% & 17.55 & 2.97 & 15.20 & 17.60 & 19.70 \\
Share of Medium Skilled Workers in \% & 63.29 & 3.75 & 60.60 & 64.00 & 65.90 \\
Share of High Skilled Workers in \% & 5.61 & 2.30 & 4.20 & 5.00 & 6.20 \\
Students per 1,000 Inhabitants & 5.18 & 14.98 & 0.00 & 0.00 & 3.20 \\
Doctors per 100,000 Inhabitants & 131.93 & 22.84 & 121.40 & 129.20 & 139.20 \\
Local Business Tax Multiplier & 339.02 & 31.12 & 320.00 & 340.00 & 352.00 \\
PIGS Stock in 1 Mio. Euro & 30.44 & 68.40 & 3.59 & 9.09 & 30.35 \\
PIGS Stock per Capita in Euro & $5,139.12$ & $2,327.23$ & $3,672.67$ & $4,733.74$ & $6,083.29$ \\
\hline Observations & 8130 & & & & \\
\hline
\end{tabular}

Notes: Calculations are based on the year 2006 and include 8,130 municipalities. The PIGS stock per capita is calculated based on the localities' population in the pre-sample year 1997. Information on the number of firm foundations per municipality stems from the Gewerbeanzeigenstatistik, PIGS information from the Jahresrechnungstatistik, data on municipalities' local business tax rates, population and unemployment rates from Statistik Lokal, all provided by the German Statistical Office. Data on skilled workers, students and doctors is drawn from the INKAR data provided by the Federal Institute for Research on Building, Urban Affairs and Spatial Development.

\section{Estimating Fiscal Policy Effects on Firm Foundation}

\section{A. Baseline Estimation}

To test for a link between local business taxes, PIGS and firm foundations, we estimate a model of the following form

$$
E\left(y_{i t} \mid \mathbf{X}_{i t}, C_{i t}, T_{i t}, \lambda_{i}, \delta_{t}\right)=\exp \left(\gamma \mathbf{X}_{i t}+\beta_{1} C_{i t}+\beta_{2} T_{i t}+\lambda_{i}+\delta_{t}\right)
$$

where $y_{i t}$ denotes the number of firm foundations in jurisdiction $i$ at time $t, C_{i t}$ the value of the total PIGS capital stock, $T_{i t}$ the local business tax and $\mathbf{X}_{i t}$ the vector of socio-economic control variables described above. The latter includes municipalities' number of inhabitants, implying that the model accounts for potential effects related to PIGS usage rivalry. ${ }^{19}$ Additionally, we control for municipality fixed effects $\lambda_{i}$ and state-year fixed effects $\delta_{t}$. We calculate cluster robust standard errors

\footnotetext{
${ }^{19}$ We believe that accounting for potential PIGS rivalry effects by adding population as a control regressor is superior to scaling the PIGS variable by population as the former, contrary to the latter, does allow for but does not impose rivalry effects. When using the PIGS capital stock scaled by population as regressor, we obtain qualitatively similar but quantitatively somewhat larger results than the ones reported in this paper.
} 
Figure 2: Average Share of PIGS Stocks in 2006

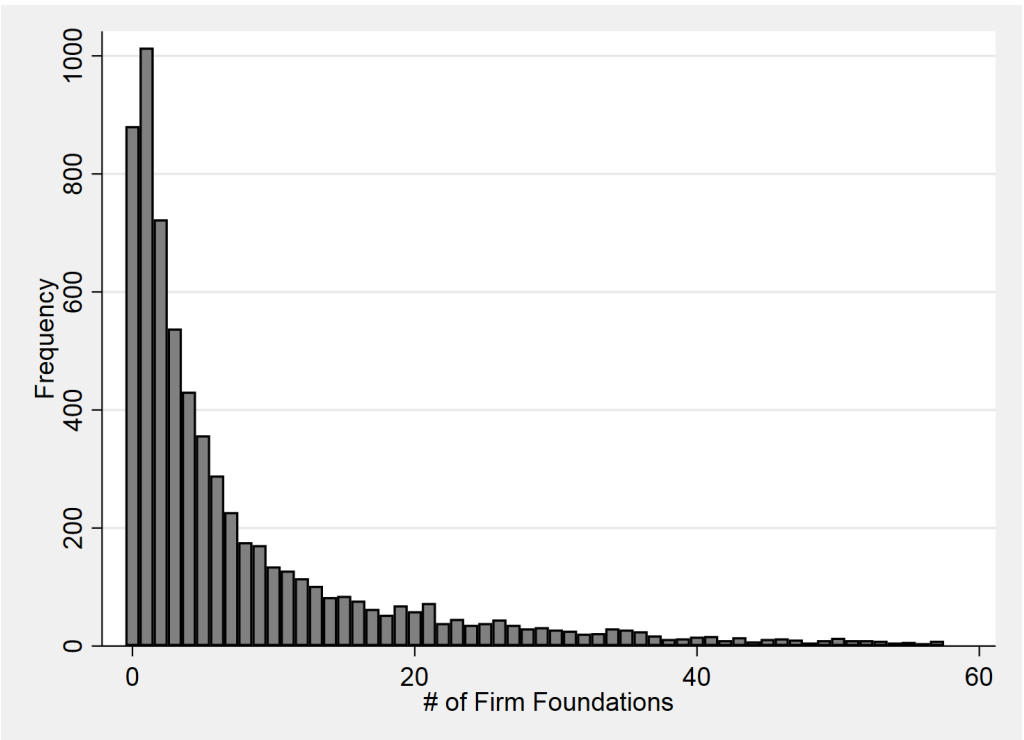

Notes: The figure depicts the distribution of firm foundation in 2001 using municipalities with a number of firm foundations less than the $95 \%$ quantile of the firm foundation distribution in 2001.

on the municipality level to allow for deviations from the Poisson distribution (see Wooldridge 2010).

The estimation results for Equation 3 are presented in Table C1 in the online appendix. The findings suggest that local business taxes (PIGS) exert a significantly negative (positive) effect on the number of new firm foundations. In quantitative terms, both effects turn out to be moderate in size. ${ }^{20}$

We do not consider these estimates to retrieve causal effects though. While the fixed effects approach in Equation 3 rules out omitted variable bias related to time-constant unobserved factors, the estimated coefficients may still be biased by reverse causality or by time-varying unobserved correlates of municipalities' policy choices and the number of new businesses. Specifically, local PIGS and taxes may vary for different underlying reasons and motives - including, changes in jurisdiction

${ }^{20}$ Note that the coefficients of a Poisson regression can be interpreted as semi-elasticies (see e.g. Cameron and Trivedi (2005)). 
characteristics like tax base mobility, jurisdiction size and agglomeration economies (see e.g. Koh et al. (2013) and Langenmayr and Simmler (2018)), changes in the partisanship of executive and legislative bodies as well as electoral cycles (see e.g. Foremny and Riedel (2014), Freier and Odendahl (2015)) or changes in neighbor policies (see, for example, Hauptmeier et al. (2012) for German municipalities). Some of these policy changes may be endogenous in the context of our empirical framework. If localities, for example, responded to declines in local economic activity and firm foundation rates with countercyclical fiscal policies (i.e. increases in PIGS spending or reductions of the local business tax rate), our baseline estimates would be biased towards zero.

\section{B. Control Function Approach and Spatial Effects}

To address these concerns, we set up the following control function approach

First Stage:

$$
\begin{gathered}
C_{i t}=\gamma_{1}^{C} \mathbf{X}_{i t}+\gamma_{2}^{C} \mathbf{Z}_{i t}+\lambda_{i}^{C}+\delta_{t}^{C}+\nu_{i t} \\
T_{i t}=\gamma_{1}^{T} \mathbf{X}_{i t}+\gamma_{2}^{T} \mathbf{Z}_{i t}+\lambda_{i}^{T}+\delta_{t}^{T}+\mu_{i t}
\end{gathered}
$$

Second Stage:

$$
E\left[y_{i t} \mid \mathbf{R}_{i t}\right]=\exp \left(\gamma \mathbf{X}_{i t}+\beta_{1} C_{i t}+\beta_{2} T_{i t}+\lambda_{i}+\delta_{t}+\hat{\nu}_{i t}+\hat{\mu}_{i t}\right)
$$

with $\hat{\nu}_{i t}$ and $\hat{\mu}_{i t}$ denoting the predicted residuals calculated from regressing $C_{i t}$ and $T_{i t}$ on the control variables $\mathbf{X}_{i t}$ and the excluded instruments $\mathbf{Z}_{i t}$ using ordinary least squares. ${ }^{21}$ Standard errors are bootstrapped with 100 draws to obtain valid standard errors when instrumenting the PIGS capital stock and the local business tax rate.

\footnotetext{
${ }^{21} \mathbf{R}_{i t}=\left\{\mathbf{X}_{i}, C_{i t}, T_{i t}, \lambda_{i}, \delta_{t}, \hat{\nu}_{i t}, \hat{\mu}_{i t}\right\}$ represents our set of regressors.
} 
We make use of two instruments. The PIGS capital stock is instrumented using variation generated by the 'Renewable Energy Sources Act' (RES Act) of 2000. This Act was initiated by the German state to promote energy production from renewable sources. Among others, the law created heavy subsidies for firms constructing wind power plants resulting in a substantial increase in the number of plants across Germany. Wind power plants are subject to local taxation and directly increase local business tax revenues. We hence expect that localities that attracted new wind power plants in the wake of the RES Act observed a surge in their local tax revenue and in consequence their local spending. ${ }^{22}$ Our instrument exploits that jurisdictions with a large amount of unpopulated land as well as high wind strength have seen the strongest increase in business tax revenues as in these jurisdiction wind power plants are more profitable (and therefore more likely to be built) and a larger number of wind power plants can be hosted. ${ }^{23}$ Following this notion, our instrument captures differences in the emergence of spending behaviour of localities with low levels of wind and/or little free agricultural space and localities with both, high levels of wind and free agricultural space, after the passing of the RES Act.

To construct the instrument, we will use the mean wind strength (from 1981 to 2000, provided by the German Weather Service) in a height of 80 meters and the total agricultural land in $\mathrm{km}^{2}$ within German municipalities. Figure (3) depicts $1 \%$ quantiles of these variables graphically. Darker colors are associated with higher quantiles. The figure suggests that wind strength and agricultural land vary substantially between localities. Especially localities in the North-West of Germany (in

${ }^{22}$ Our first stage results confirm the notion that communities with high levels of wind strength and significant free agricultural space increased their local PIGS spending in the wake of the RES Act (see below). Alternatively, localities might respond to the additional tax revenue from the new wind power plant activity by lowering their local business tax rates. Our first stage models allow for this possibility as we also augment the first stage model for the local business tax rate by the described wind energy instrument.

${ }^{23}$ The latter follows from the fact that guidelines for approving the construction of wind power plants in Germany state that the typical distance of an energy production area with seven wind power plants from the next local town should be at least 1500 meters. 
Figure 3: Quantiles of Mean Wind Strength and Agricultural Land

(a) Mean Wind Strength in $80 \mathrm{~m}$ Height

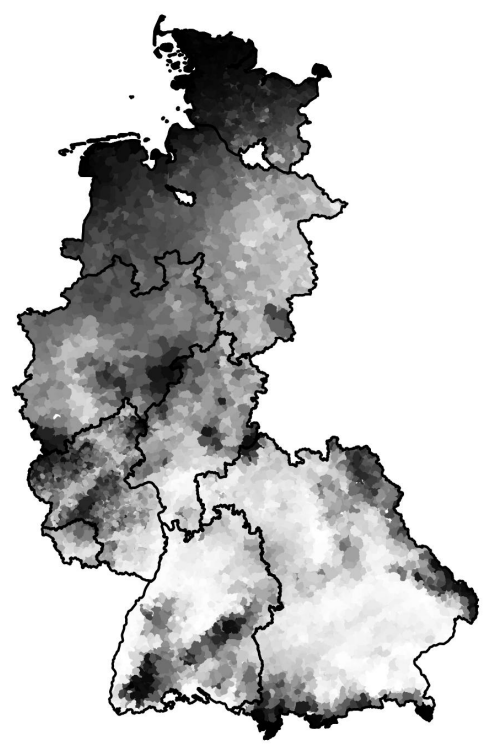

(b) Mean Agricultural Land

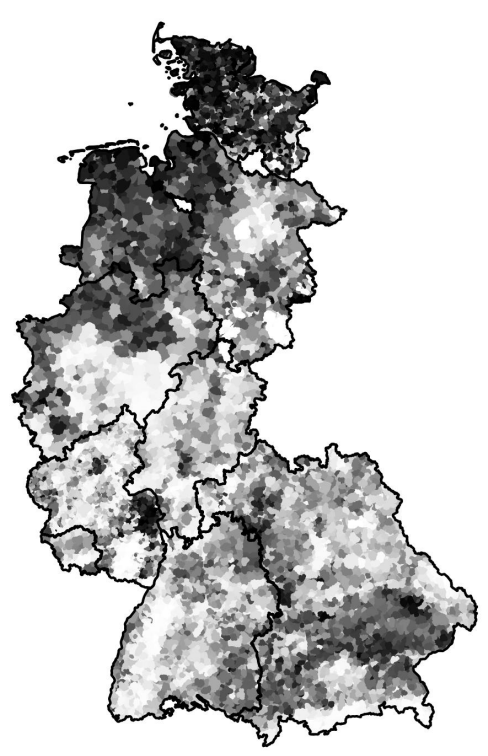

Notes: The figure depicts the quantiles of mean wind strength in $80 \mathrm{~m}$ height and mean fraction of agricultural land in West German communities. Darker colors are associated with higher quantiles.

Lower-Saxony and Schleswig-Holstein) are likely to observe high wind strength and sufficient agricultural land. The empirical analysis to come will rely on variation in wind strength and free agricultural space within states by including a full set of state-year fixed effects as control variables.

Furthermore note that the construction of the instrument relies on the assumption that (most of) the profits of wind turbines are taxed in the host location of the wind turbine. If local wind power plants are organized within separate legal entities, this obviously holds true. ${ }^{24}$ If they are part of larger groups that span several jurisdictions, the local business tax base is apportioned across jurisdictions according to

\footnotetext{
${ }^{24}$ Note that wind power plants, if organized in separate legal entities, commonly are set up as unincorporated businesses. As these entities do not employ any personal, they are not counted as a firm foundation in the definition of our dependent variable. We are hence confident that our main estimates do not pick up mechanical effects related to the foundation of entities for wind power plants. To corroborate this point, we present robustness checks below.
} 
a formula apportionment system with profit consolidation at the federal level and payroll apportionment. While the operation of wind power plants commonly does not involve any labour and thus wage payments, the German local business tax law acknowledges that the allocation of the tax base does not have to be based on the payroll factor if this mechanism leads to an unfair tax base allocation (Art. 33, Local Business Tax Law). Anecdotal evidence suggests that, during our sample period, wind turbine jurisdictions received a significant fraction of wind turbine profits based on this legal provision and the notion that there is, in general, little labour involved in electricity generation. Langenmayr and Simmler (2018) simulate wind turbine profits in Germany assuming that profits are taxed in the host jurisdiction of the wind turbine. When regressing the observed actual local business tax base on the simulated profits, they find a strong correlation between the two measures. ${ }^{25}$

Furthermore note that we will cross-check the sketched instrumental variable strategy by also running regressions where we instrument locality spending with agricultural land used for corn production in German municipalities interacted with post RES 2000 reform indicators. The rationale for that robustness check is that the introduction of the RES Act also heavily subsidized bio-energy production and thereby increased prices for corn and thus profits of corn-farmers, which again are subject to local business taxation (see, e.g., Habermann and Breustedt (2011). ${ }^{26}$

On top of that, the local business tax rate is instrumented with the so-called 'reference business tax' from the German municipal fiscal equalization scheme. Municipal fiscal equalization is organized through fiscal transfers from the state level

${ }^{25}$ After our sample period, from 2009 onwards, an explicit allocation mechanism for wind turbines was introduced in the local business tax law, stating that $30 \%$ of the tax base from wind turbine activity are to be allocated according to wages (and thus, commonly, to the management jurisdiction of the group) and $70 \%$ are to be allocated according to fixed assets, excluding office furniture and equipment (and thus, commonly, to the wind turbine jurisdiction) (Art. 29, Par. 2 Local Business Tax Law).

${ }^{26}$ Since agricultural land use data is not available on the municipality level, we use county level information on the share of agricultural land used for corn production multiplied with the size of agricultural land in a jurisdiction to construct the variable. 
to the municipality level. If a municipality's fiscal capacity falls short from its fiscal needs, it receives funds from the state level (while it commonly does not have to give up funds if fiscal needs fall short from fiscal capacity). Note that fiscal needs are a conceded budget per resident, while fiscal revenues are a measure for tax revenues at standardized tax rates. ${ }^{27}$ Local business tax revenues add to localities' fiscal capacity at such a standardized 'reference business tax rate'. This implies that, if the reference tax is larger than the municipality's actual tax rate, localities appear richer in the equalization scheme than they actually are and vice versa. Anecdotal evidence suggests that municipalities respond to changes in the position of their reference tax relative to the actual tax rate: If the reference tax is increased above the actual rate, local municipal councils, with an elevated propensity, adjust the business tax rate upwards (see e.g. IHK (2016)). The reference tax hence acts as an anchor for the choice of municipalities' local business tax rate. Figure 4 depicts the distribution of local business tax multipliers relative to the reference tax for our sample localities. The picture shows that municipalities, in line with the above considerations, bunch at the reference tax rate from below. The spike in the distribution, moreover, moves when the reference tax changes. To illustrate this, Figure B1a in the Appendix depicts the distribution of local business rates in 1998 for the state of North-Rhine Westfalia, which is in the largest German state as measured by population and GDP. In line with Figure 4, there is clear bunching at the reference tax multiplier in 1998. Figure B1b, moreover, depicts the distribution of the local business tax multiplier in 2006 after the reference tax in North-Rhine Westfalia was increased. The figure shows clear bunching at the new higher reference tax rate - the spike in the distribution had moved to the new reference tax value. Following these anecdotal and empirical considerations, we instrument the local business

\footnotetext{
${ }^{27}$ The rationale for measuring fiscal capacity as tax revenues at standardized rather than actual tax rates is to avoid that municipalities lower their local business and property tax rates in order to lower their fiscal capacity in the fiscal equalization scheme.
} 
tax choices with a dummy variable indicating if the reference tax rate in the fiscal equalization scheme is smaller or larger than a municipality's actual local business tax rate. To avoid obvious endogeneity concerns, the reference tax is compared to the actual rate in a pre-sample period (1997), implying that time variation in the reference tax instrument relates to adjustments in the reference tax only.

Figure 4: Distribution of the Local Business Tax Relative to the Reference Tax

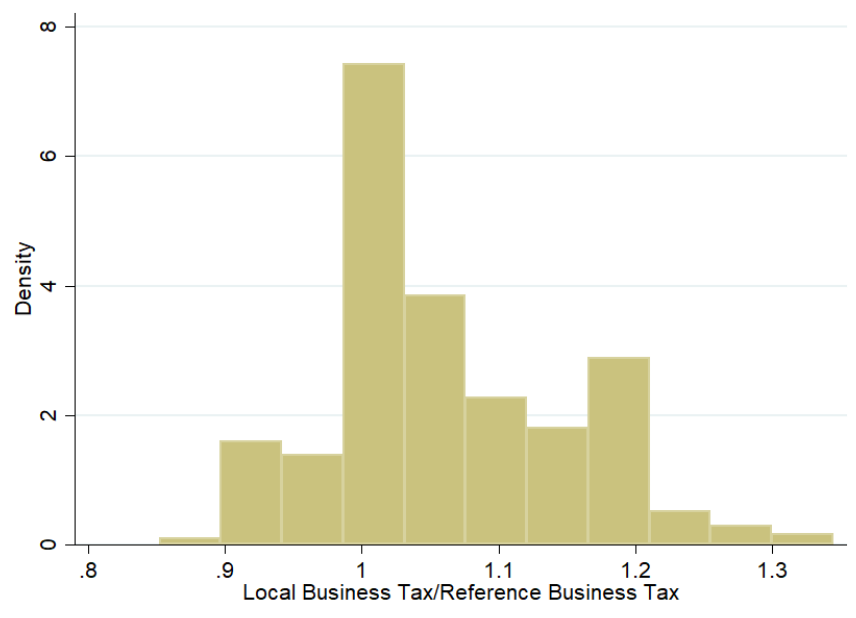

Notes: The figure depicts the ratio of our sample localities' local business tax and the reference tax rate applied in the fiscal equalization scheme of the hosting state.

Furthermore, we extend the sketched control function approach by adding the spatial lags of the tax and PIGS regressors to the estimation model. Formally, the second stage model reads

$$
E\left[y_{i t} \mid \mathbf{R}_{i t}\right]=\exp \left(\gamma \mathbf{X}_{i t}+\beta_{1} C_{i t}+\beta_{2} T_{i t}+\beta_{3} \bar{C}_{i t}+\beta_{4} \bar{T}_{i t}+\lambda_{i}+\delta_{t}+\hat{\nu}_{i t}+\hat{\mu}_{i t}+\hat{\phi}_{i t}+\hat{\rho}_{i t}\right)
$$

where $\hat{\nu}_{i t}, \hat{\mu}_{i t}, \hat{\phi}_{i t}$ and $\hat{\rho}_{i t}$ denote the error terms from first stage models for the local business tax, the PIGS capital stock and the spatial lags of the two policy variables, with the latter being defined as $\bar{C}_{i t}=\sum_{j} W_{i j} C_{j t}$ and $\bar{T}_{i t}=\sum_{j} W_{i j} T_{j t}$, where $j$ 
indicates neighboring jurisdictions of municipality $i$, with $i \neq j . T_{j t}$ and $C_{j t}$ stand for the local business tax and the PIGS capital stock in neighboring jurisdiction $j$ at time $t$ and $W_{i j}$ depicts the weight of $j$ in the calculation of this average. In the baseline analysis, we will employ inverse distance weights and condition on neighbors in a 15 kilometer distance radius; formally $W_{i j}=I_{i j}^{15} \frac{1 / d_{i j}}{\sum_{j} 1 / d_{i j}}$, where $I_{i j}^{15}$ is an indicator equal to 1 if municipality $j$ is within a 15 kilometer distance radius of municipality $i$ and $d_{i j}$ depicts the distance between $i$ and $j$. In robustness tests, we assess the sensitivity of our estimates to alternative weighting schemes.

Augmenting the estimation model by spatial lags serves two purposes: Firstly, it allows us to test for fiscal externalities of tax and PIGS choices on other jurisdictions; such cross-border effects are of economic relevance as they, e.g., convey to what extent increases in the number of firm foundations in the policy-reforming country reflect activity that is attracted from other jurisdictions or genuinely new activity. Moreover, adding the spatial lag of the policy variables to the set of regressors is necessary to avoid bias in the coefficient estimates that capture the tax and PIGS effects on the foundation of new firms in the policy-changing jurisdictions. To see this, consider a jurisdiction that decreases its local business tax rate. If policy choices are positively correlated across space (as predicted by tax competition models, see e.g. Devereux et al. (2008)), this tax reduction triggers a decrease in the local business tax of neighbouring localities as well. While the decline in the host jurisdiction tax exerts a positive effect on the number of firm foundations, the decrease in neighboring communities' tax rates is expected to depress the number of firm foundations in the considered jurisdiction. If spatial effects are not modelled, the coefficient estimate for the jurisdiction's own tax variable captures the joint effect of both tax policy adjustments and hence underestimates the impact of the own tax instrument in absolute terms. Analogous considerations, moreover, apply 
in the PIGS dimension.

Furthermore note that this type of endogeneity problem is not solved by instrumenting for the own-policy effects as described above if changes in the instruments are correlated across space. ${ }^{28}$ We hence account for spatial lags of the PIGS capital stock in our control function model, treating the policy variables as well as the spatial lags as endogenous. Specifically, we estimate four first stage equations which regress the local business tax, the PIGS stock and the spatial lags of the two policy measures on the wind instrument and the reference tax instrument sketched above as well as the spatial lags of the instruments and the set of control variables and their spatial lags. The predicted residuals from the four first stage regressions are included as regressors in the second stage model (cf. Equation 5).

\section{Estimation Results}

The baseline estimates for our control function approach are reported in Table 2 and Table B2 in Appendix B, with Table 2 (Table B2) depicting the results of the second (first) stage model. Columns (1) and (2) of Table 2 present control function models, where the local business tax rate and the PIGS stock are included as sole policy regressors. Specification (3) jointly includes both policy variables and Specification (4) estimates the full model additionally including the spatial lags of the policy regressors.

The first stage results in Table B2 of the Appendix are as expected and confirm our considerations in the previous chapter. An increase in the reference business tax triggers an increase in the local business tax rate for municipalities which had a tax rate above or equal to the reference tax rate before the increase and would have had a tax rate below after the increase (cf. Column (1) of Table B2 in the Appendix).

\footnotetext{
${ }^{28}$ Such correlations plausibly often do exist: In our case, the exposure to wind and the availability of agricultural land may very well be correlated across space as may be changes in the position of the jurisdiction's tax rate relative to the reference tax.
} 
On top of that, the RES instrument has the expected positive sign in the first stage model for PIGS provision, suggesting that PIGS indeed significantly increase when localities obtain additional business tax revenues from wind turbines (cf. Column (2) of Table B2 in the Appendix). In models with both endogenous policy regressors and both instruments, the coefficient estimate for the reference tax instrument only turns out statistically significant in the first stage model for the local business tax regressor; the coefficient estimates for the RES instrument turns out positive and statistically significant in the first stage model for the PIGS regressor and negative and statistically significant for the tax regressor (cf. Columns (3) of Table B2). The latter effect vanish, however, once we include the instruments for the spatial lags (cf. Column (4)). ${ }^{29}$ On top of that, analogous result patterns emerge for the first stage effect of the spatial lags of the instrumental variables on the spatial lags of the local business tax choice and PIGS provision (cf. Columns (4) of Table B2 in the Online Appendix). The spatial lags of the instruments, however, also influence the own local business tax and PIGS variables as well as the spatial lag of the other policy dimension. This likely roots in fiscal interactions between municipalities as documented in prior literature (see e.g. Solé-Ollé (2006), Devereux et al. (2008), Winner (2012)).

The results of the second stage models confirm a statistically significant impact of local business tax and PIGS choices on firm foundation rates. The coefficient estimates for the local business tax (PIGS stock) turn out negative (positive) and statistically significant across specifications. Quantitatively, the control function estimates are significantly larger than the baseline estimates in absolute terms, sug-

\footnotetext{
${ }^{29}$ This result pattern is thus in line with the considerations laid out in the previous section. As expected, our reference tax instrument affects the local business tax choice of communities only. On top of that, additional revenues obtained by localities with high levels of wind and free agricultural space in the wake of the RES indeed translate in additional PIGS spending rather than lower local business tax rates. This is consistent with the predictions of the literature on fiscal bias (see e.g. Tabellini and Alesina (1990), Krogstrup and Wyplosz (2006), Rattsø (2004)).
} 
gesting that endogeneity issues along the lines discussed above bias coefficient estimates in the baseline setting. Specification (4) suggests that the elasticity of firm foundations w.r.t. local business tax changes amounts to $-4.6 .^{30}$ This is comparable to recent estimates in regional contexts by Becker et al. (2012) for Germany and by Suárez Serrato and Zidar (2016) for the US, but tends to be at the upper end of estimated business activity responses to corporate taxation in international contexts (see e.g. deMooji and Ederveen (2003) and Feld and Heckemeyer (2011) for surveys).

Table 2: Control Function Poisson Regressions

\begin{tabular}{lcccccc}
\hline Radius, Spatial Lag & & & & $15 \mathrm{~km}$ & $20 \mathrm{~km}$ & $40 \mathrm{~km}$ \\
& $(1)$ & $(2)$ & $(3)$ & $(4)$ & $(5)$ & $\begin{array}{c}4 \\
(6)\end{array}$ \\
\hline LB Tax & $-0.0083^{* * *}$ & & $-0.0084^{* * *}$ & $-0.0137^{* *}$ & $-0.0121^{* *}$ & $-0.0095^{* *}$ \\
& $(0.0019)$ & & $(0.0021)$ & $(0.0055)$ & $(0.0050)$ & $(0.0043)$ \\
LB Tax, Spatial Lag & & & & $0.0188^{* * *}$ & $0.0149^{* *}$ & 0.0065 \\
& & & & $(0.0065)$ & $(0.0061)$ & $(0.0064)$ \\
PIGS & & $0.0199^{* *}$ & 0.0120 & $0.0257^{* * *}$ & $0.0223^{* * *}$ & $0.0154^{*}$ \\
& & $(0.0086)$ & $(0.0081)$ & $(0.0086)$ & $(0.0079)$ & $(0.0086)$ \\
PIGS, Spatial Lag & & & & 0.0327 & 0.0154 & -0.0396 \\
& & & & $(0.0273)$ & $(0.0276)$ & $(0.0317)$ \\
\hline N & 70653 & 70653 & 70653 & 70653 & 70653 & 70653 \\
Municipality FE & $\checkmark$ & $\checkmark$ & $\checkmark$ & $\checkmark$ & $\checkmark$ & $\checkmark$ \\
State X Year FE & $\checkmark$ & $\checkmark$ & $\checkmark$ & $\checkmark$ & $\checkmark$ & $\checkmark$ \\
Controls & $\checkmark$ & $\checkmark$ & $\checkmark$ & $\checkmark$ & $\checkmark$ & $\checkmark$ \\
Control Functions & $\checkmark$ & $\checkmark$ & $\checkmark$ & $\checkmark$ & $\checkmark$ & $\checkmark$ \\
\hline
\end{tabular}

Notes: The table reports the second stage results for the control function approach presented above, where the local business tax, the PIGS stock and the spatial lag of the two variables are treated as endogenous. The dependent variable is the number of firm foundations per municipality and year. Spatial lags in Column (4), (5) and (6) are constructed based on neighbors within 15, 20 and $40 \mathrm{~km}$ distances respectively and inverse-distance weighted. The model includes a full set of state-year fixed effects and the control variables described in Section 3 as well as their spatial lags. Bootstrapped standard errors in parentheses. ${ }^{*},{ }^{*},{ }^{* * *}$ denote significance at the 10,5 and $1 \%$ level.

Specification (4), moreover, yields a positive and quantitatively large coefficient estimate for the spatial lag of the local business tax variable, suggesting that higher business taxes push out new firms to locate in neighboring localities. As the point estimates for the own tax effects and the spatial lag do not significantly differ in absolute terms, the results point to strong beggar-thy-neighbor effects: increases

\footnotetext{
${ }^{30}$ Note that a $1 \%$-change in the local business tax rate corresponds to an increase by 3.39 business tax points on average (cf. Table 1), which according to the estimate translates in a drop in the number of new firms by $4.644 \%(=3.39 \cdot(-0.0137))$.
} 
in the number of firm foundations when local business taxes decline are suggested to largely reflect that businesses are attracted from neighboring jurisdictions as opposed to the emergence of genuinely new economic activity.

The model, moreover, suggests that PIGS exert a significantly positive impact on the number of new firms in the policy-changing jurisdiction. In quantitative terms, the elasticity to the PIGS capital stock is determined with $0.78 .{ }^{31}$ The coefficient estimate for the spatial lag of the PIGS stock, moreover, while positive, does not gain statistical significance, rejecting that PIGS exert a significant impact on the number of new firm foundations in neighboring municipalities. While, in Specification (4), spatial lags are constructed accounting for neighbors in a 15 kilometer distance radius, similar results are derived when the calculation of the spatial lags accounts for neighbors in a 20 or 40 kilometer distance radius (cf. Columns (5) and (6)).

The estimates hence suggest that local policies matter: Reductions in local business taxes and increases in the PIGS capital stock, ceteris paribus, do raise the number of firm foundations. The quantitative effect of local business taxes, thereby, tends to be larger than the effect of PIGS provision. The estimates in Column (4) of Table 2 suggest that it requires an increase in the PIGS stock by 1 Million Euro to raise the number of firm foundations by $2.3 \%$. Assuming that the capital stock depreciates over 10 years, this corresponds to additional PIGS spending of 100,000 Euros per year. To achieve the same increase in the number of firm foundations through a decline in the local business tax rate, in turn, required a reduction in the local business tax multiplier by around 2 multiplier points or about 0.1 percentage points $(=2 \cdot 0.05$, cf. Section III A) only, which would results in a negligible reduc-

\footnotetext{
${ }^{31} \mathrm{An}$ increase in the PIGS capital stock by $1 \%$ corresponds to a rise by 0.34 Million Euro on average (cf. Table 1) and is estimated to trigger a drop in the number of new firms by $0.78 \%$ (= $0.34 \cdot 0.0257)$. Note, moreover that, as described in the Introduction, we are not aware of other papers that estimate the link between local PIGS provision and firm activity. Countrylevel estimates in Bénassy-Quéré et al. (2007) also suggest a positive link between government spending and firm activity, which is quantitatively smaller than our estimate though.
} 
tion of local business tax revenues only. ${ }^{32}$ Given that local business taxes and PIGS spending are connected by the government budget, this suggests that local policy makers can raise the number of firm foundations in their jurisdictions by simultaneously reducing the local business tax rate and PIGS. ${ }^{33}$ Our findings, however, also indicate that local business tax reductions attract firms from neighboring jurisdictions rather than triggering genuinely new firm foundations. While analogous cross-border effects are rejected for PIGS in the full sample, we will show below that they do emerge for some PIGS dimensions and some subsets of firms. This supports local public sector models, where fiscal interactions root in firm mobility across jurisdiction borders. Our estimates do not allow us to differentiate between different models, however, and draw welfare conclusions. The latter critically depend on the sign and size of policy interactions between local jurisdictions, which is still debated in the literature (see, e.g., Devereux et al. (2008), Hauptmeier et al. (2012), Chirinko and Wilson (2017), Baskaran and Hessami (2014), Parchet (2019)).

\section{Robustness Checks}

Tables 3 to 5 present robustness checks. Firstly, we rerun the models using different definitions of the spatially lagged regressors. Table 3 presents specifications that reestimate our baseline model, constructing the spatial lags of regressors based on uniform weights (Columns (1) to (3)), squared inverse distance weights (col. (4) to (6)) and population weights (col. (7) to (9)), again accounting for neigh-

\footnotetext{
${ }^{32}$ Abstracting from behavioural adjustments, this would reduce the local business tax revenues of the average community by around 300 Euros only ( $0.01 \%$ of municipalities' average business tax revenues of around 300,000). As behavioural adjustments are expected to buffer the negative revenue consequences, this might even be an upper bound to the true revenue loss.

${ }^{33}$ Note, however, that, while local business taxes and PIGS are connected by the government budget, changes in either policy instrument do not automatically trigger adjustments of the other instrument. Specifically, the majority of revenues of German municipalities comes from other sources than local business taxation (most importantly grants from central governments and revenues from centrally collected personal income and value added taxes, cf. Section III A); PIGS may, therefore, change without adjustments in the local business tax rate. Inversely, additional revenues from increased local business tax rates may be used to repay debt rather than finance new PIGS.
} 
bors within a 15/20/40 kilometer distance radius respectively. Overall the results confirm our baseline estimates but suggest that tax competition effects between neighboring communities quickly fade out in geographic distance. ${ }^{34}$ Moreover, we find somewhat smaller estimates for the tax coefficient when population weights are used to construct the spatial lag of the local business tax rate. This may reflect that agglomeration rents reduce the sensitivity of firm location choices to changes in policy instruments when neighboring jurisdictions are large. ${ }^{35}$

Moreover, we check on the validity of our instrumental variable strategy. First, we dropped all control variables as almost all of them may be outcomes as well. While endogenous control variables are not necessarily problematic, they may be so if they are confounded and a function of the instrument (see, for example, Deuchert and Huber (2017)). The estimates without control variables are presented in Column (1) of Table 4 and show that excluding the control variables changes neither the qualitative nor the quantitative result. ${ }^{36}$

\footnotetext{
${ }^{34}$ Note that the results imply that distant neighbors' policy choices do not exert a direct effect on firm foundations in a considered municipality. They might exert an indirect effect though. If spatial policy choices are correlated in space, idiosyncratic shocks to distant neighbors' policies may change the policy choices of the considered jurisdiction and/or its direct neighbors and through this channel indirectly affect the number of new firms in the considered municipality. Our empirical analysis yields unbiased estimates for the latter effects (changes in firm foundations in response to own and direct neighbors' policy choices).

${ }^{35}$ From a theoretical perspective, the effect of neighbor size on the cross-border effect of public policies a unclear. On the one hand, policy changes in neighboring jurisdictions may exert a larger effect on firm foundations if the affected neighbour is large. If a neighboring city with 10,000 firms increases its local business tax rate, more firms may relocate to a considered locality than if a neighboring municipality with 50 firms increases its tax rate. On the other hand, firms may obtain agglomeration rents when locating in large jurisdictions, which may make location choices less responsive to policy changes. As point estimates decrease, our results suggest that the latter effect dominates (note, however, that confidence bounds are substantial and statistical difference is not given). Note that we use pre-sample population weights in the latter case and only apply them when calculating the neighbors' average local business tax. The rationale for this strategy is that the PIGS variable is not normalized on population, implying that cross-sectional and longitudinal variation in PIGS already reflect size difference between municipalities. Finally note that a recent paper by Wittrock (2018), based on the same data as the one used in our study, shows that firms respond less sensitively to PIGS and tax changes in the presence of agglomeration and localization rents.

${ }^{36}$ In the appendix, we furthermore show that population size and the unemployment rate, which serve as municipal-level control variables in our empirical analysis, are indeed correlated with the instrumental variables, conditional on municipality and state-year fixed effects (see Table
} 


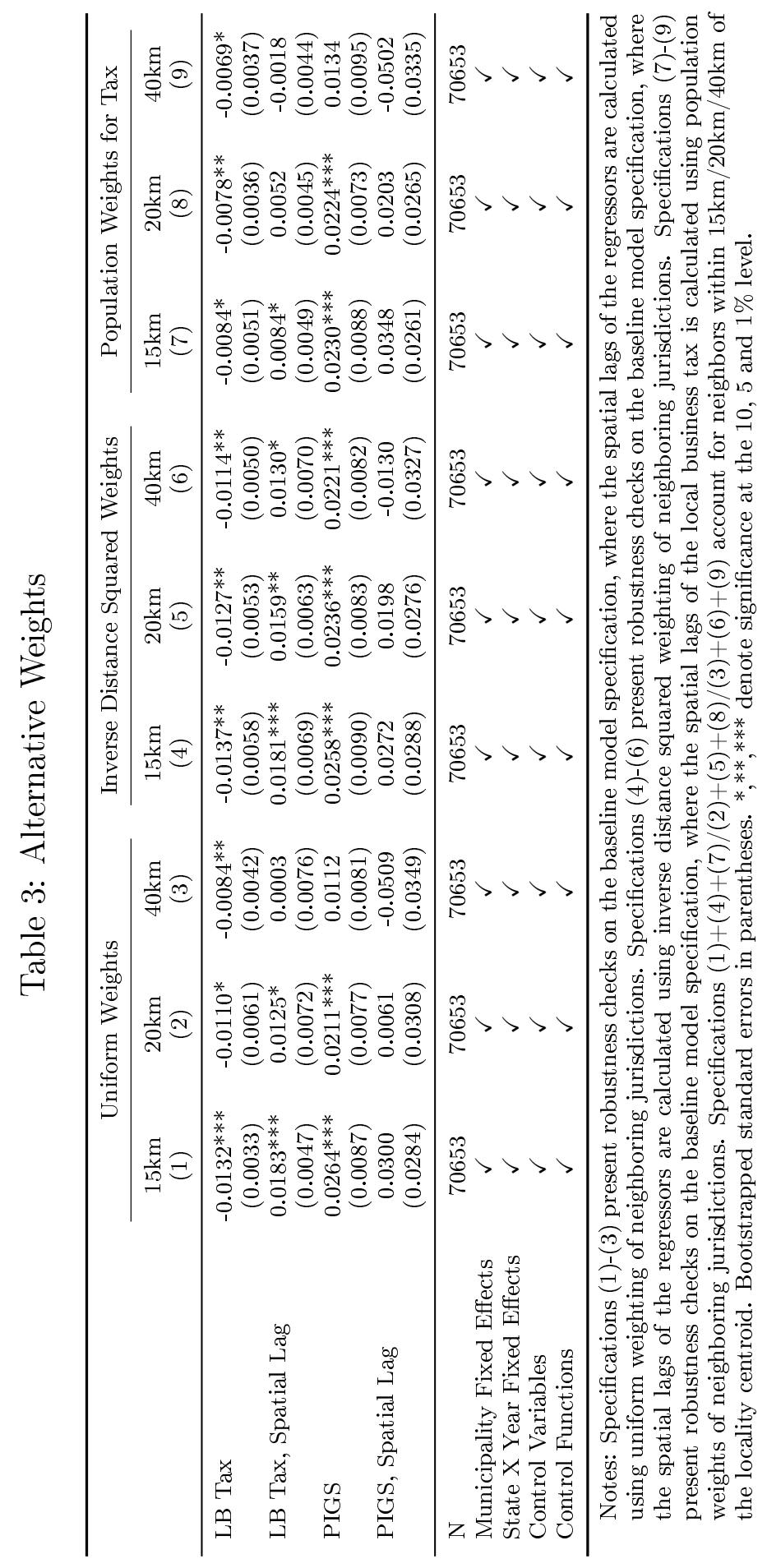


Specifications (2) to (6) of Table 4, moreover, assess whether our findings might be confounded by differences in underlying firm foundation trends across our sample jurisdictions. One particular concern might be that the RES instrument relies on variation in wind levels as well as agricultural space across our sample municipalities. Our estimates would hence be biased if localities with much and little agricultural space - that may differ in population size, economic activity and geographic location - would be subject to different underlying firm foundation time trends. To assess this possibility, we define indicators for the deciles of the municipal population distribution and add interactions between these indicators and a full set of year fixed effects to the vector of regressors in Specification (2). This leaves our estimates largely unchanged. Along the same lines, Specification (3) defines indicators for the deciles of the municipal distance distribution to the next large city (defined as cities with more than 100,000 inhabitants in 1997) and adds interactions between these indicators with a full set of year fixed effects. This again leaves the results qualitatively and quantitatively unchanged. Specifications (4)-(6) show that the same holds true when we add agricultural land decile indicators interacted with year dummies or when we exclude localities with high and low levels of agricultural land (top or bottom 25\%) from the estimation sample. Note, moreover, that results are also largely unchanged when we include commuting zone-year instead of stateyear fixed effects (see Column (2) in Table B4 in the online appendix) and augment the baseline set of regressors by additional control variables for the partisanship of the municipal council (cf. Column (3) of Table B4 in the online appendix). ${ }^{37}$

B3). This suggests that they may be endogenous to changes in the instrument. As indicated in the main text, their inclusion in the estimation model does not alter our coefficient estimates of interest though.

${ }^{37}$ Note that the sample size differs in the specifications in Table B4 differs from the baseline specification as we were unable to merge commuting zone information, the share of the political parties as well as wind turbine information to our main data for two German states (BadenWürttemberg and Saarland). The reason is that access to the Gewerbeanzeigenstatistik was granted separately for individual German states by the State Statistical Offices in charge. Data access is organized via a common data lab of the statistical offices and via remote data access. 
Table 4: Sensitivity Control Function Approach

\begin{tabular}{|c|c|c|c|c|c|c|}
\hline \multirow[t]{2}{*}{ Sample } & \multicolumn{4}{|c|}{ Baseline } & \multicolumn{2}{|c|}{ Share Agr } \\
\hline & (1) & $(2)$ & $(3)$ & $(4)$ & $\frac{>\text { P } 25}{(5)}$ & $\frac{<\text { P75 }}{(6)}$ \\
\hline LB Tax & $\begin{array}{c}-0.0141^{* * *} \\
(0.0050)\end{array}$ & $\begin{array}{c}-0.0150^{* *} \\
(0.0062)\end{array}$ & $\begin{array}{c}-0.0130^{* *} \\
(0.0055)\end{array}$ & $\begin{array}{c}-0.0142^{* * *} \\
(0.0041)\end{array}$ & $\begin{array}{c}-0.0074 \\
(0.0058)\end{array}$ & $\begin{array}{c}-0.0157^{* * * *} \\
(0.0055)\end{array}$ \\
\hline LB Tax, Spatial Lag & $\begin{array}{c}0.0181 * * * \\
(0.0059)\end{array}$ & $\begin{array}{c}0.0214 * * * \\
(0.0070)\end{array}$ & $\begin{array}{c}0.0179 * * * \\
(0.0062)\end{array}$ & $\begin{array}{c}0.0197 * * * \\
(0.0063)\end{array}$ & $\begin{array}{c}0.0119 * * \\
(0.0058)\end{array}$ & $\begin{array}{c}0.0211^{* * * *} \\
(0.0075)\end{array}$ \\
\hline PIGS & $\begin{array}{c}0.0285^{* * *} \\
(0.0079)\end{array}$ & $\begin{array}{c}0.0384^{* *} \\
(0.0157)\end{array}$ & $\begin{array}{c}0.0255^{* * *} * \\
(0.0084)\end{array}$ & $\begin{array}{c}0.0366^{* * * *} \\
(0.0127)\end{array}$ & $\begin{array}{c}0.0356^{* * *} \\
(0.0111)\end{array}$ & $\begin{array}{c}0.0172^{* * *} \\
(0.0052)\end{array}$ \\
\hline PIGS, Spatial Lag & $\begin{array}{c}0.0257 \\
(0.0280)\end{array}$ & $\begin{array}{c}0.0309 \\
(0.0231)\end{array}$ & $\begin{array}{c}0.0329 \\
(0.0291)\end{array}$ & $\begin{array}{c}0.0177 \\
(0.0346)\end{array}$ & $\begin{array}{l}0.0434^{*} \\
(0.0241)\end{array}$ & $\begin{array}{c}0.0415 \\
(0.0275)\end{array}$ \\
\hline $\mathrm{N}$ & 70653 & 70653 & 70653 & 70653 & 52956 & 53087 \\
\hline State-Year FE & $\checkmark$ & $\checkmark$ & $\checkmark$ & $\checkmark$ & $\checkmark$ & $\checkmark$ \\
\hline Municipality FE & $\checkmark$ & $\checkmark$ & $\checkmark$ & $\checkmark$ & $\checkmark$ & $\checkmark$ \\
\hline Controls & & $\checkmark$ & $\checkmark$ & $\checkmark$ & $\checkmark$ & $\checkmark$ \\
\hline Control Functions & $\checkmark$ & $\checkmark$ & $\checkmark$ & $\checkmark$ & $\checkmark$ & $\checkmark$ \\
\hline Pop Deciles-Year FE & & $\checkmark$. & & & & \\
\hline Distance Decile-Year FE & & & $\checkmark$ & & & \\
\hline Agr Deciles-Year FE & & & & $\checkmark$ & & \\
\hline
\end{tabular}

Notes: Specification (1) reports the results when excluding the set of control variables. In Specification (2) we add population-decile year fixed effects; in Specification (3) distance to the next large city decileyear fixed effect and in Specification (4) agricultural space decile year fixed effects. Specification (4) and (5) exclude jurisdictions with a share of agricultural land in the bottom and top $25 \%$ of the distribution respectively. Bootstrapped standard errors in parentheses. ${ }^{*}, * *, * * *$ denote significance at the 10,5 and $1 \%$ level.

On top of that, we run several robustness checks to address endogeneity concerns related to the notion that the erection of wind power plants may directly impact on our dependent variable - either because new wind power plants are, themselves, counted as new establishments or because wind power plants exert a direct positive effect on the local economy. We consider neither to be of importance for our analysis. Firstly, wind turbines have mostly been erected by individuals (without any full-time employees) and are thus not counted as new establishments in our analysis (see the definition of our dependent variable in Section III). Secondly, we used data on the actual erection of wind turbines in our sample jurisdictions to crosscheck on that point and defined modified dependent variables, where we substract actually

All states, with the exception of Baden-Württemberg and Saarland, on top, allowed us to export the aggregate number of firm foundations per community and year. As linking the Gewerbeanzeigenstatistik with external information is restricted to variables that researchers initially applied for, we were unable to merge the additional data as they were not part of our initial project proposal. The specifications in Table B4 are estimated based on the exported firm count data for the other states. For comparison, Specification (1) of Table B4 reestimates our baseline model (Specification (4) of Table 2) in the restricted sample. 
erected turbines from the number of new establishments in a given municipality and year. The results are reported in Specifications (4) and (5) of Table B4. In Specification (4), the dependent variable is the number of new establishments per municipality and year less 1 in years in which new wind power plants were erected (hence assuming that new turbines were erected by the same new firm). ${ }^{38}$ In Specification (5), the dependent variable is the number of newly established firms in a municipality and year less the actual number of newly erected wind turbines (hence assuming that each wind turbine is erected by a separate new firm). The results indicate that the described modification of the dependent variable, in line with our considerations above, affects coefficient estimates neither qualitatively nor quantitatively. As spelled out above, a second concern may be that the erection of wind power plants might have a direct positive effect on the local economy. We consider this to be highly unlikely as the installation and maintenance of wind turbines requires highly specialized skills and equipment and is hence organised in firms that work on a supra-regional basis. To further assess the robustness of our findings, we rerun the analysis with an alternative instrument. Specifically, the RES 2000 act next to subsidies for wind energy production - also granted generous subsidies for the production of bio fuel (see Section III for details). As this increased the profits of farmers and the tax revenues of their host communities, we exploit differences in the emergence of revenues and spending between communities with high and low capacities for corn production after the act was passed for empirical identification (see Section III for the definition of 'capacity for corn production'). ${ }^{39}$ The second stage results are presented in Column (6) of Table B4 and, reassuringly, turn out to be qualitatively and quantitatively similar to our baseline estimates.

\footnotetext{
${ }^{38}$ The wind turbine data has been obtained from the operator database (http://www.btrdb.de/). ${ }^{39}$ Specifically, the corn capacity variable defined in Section III is interacted with an indicator for years after the implementation of the RES 2000 act and, additionally, with a linear time trend for the post reform years.
} 
Furthermore, we assess to which extent excluding large jurisdictions affects our results. In the baseline specification, we exclude jurisdictions with more than 300,000 inhabitants (top $0.25 \%$ ). Table 5 shows that similar results emerge in the full sample of jurisdictions (Column (1)), when we exclude jurisdictions with a population in the top $0.1 \%$ (jurisdictions with more than 510,000 inhabitants, cf. Column (2)) or jurisdictions with a population in the top $0.5 \%$ (jurisdictions with more than 140,000 inhabitants, cf. Column (3)).

Table 5: Sensitivity Large Jurisdictions

\begin{tabular}{lccc}
\hline Sample & $\begin{array}{c}\text { All Jurisdic. } \\
(1)\end{array}$ & $\begin{array}{c}<99.9 \% \\
(2)\end{array}$ & $\begin{array}{c}<99.5 \% \\
(3)\end{array}$ \\
\hline LB Tax & $-0.0157^{* * *}$ & $-0.0139^{* *}$ & $-0.0072^{*}$ \\
& $(0.0052)$ & $(0.0055)$ & $(0.0041)$ \\
LB Tax, Spatial Lag & $0.0198^{* * *}$ & $0.0189^{* * *}$ & $0.0124^{* *}$ \\
& $(0.0060)$ & $(0.0057)$ & $(0.0051)$ \\
PIGS & 0.0180 & $0.0289^{* * *}$ & $0.0318^{* * *}$ \\
& $(0.0125)$ & $(0.0097)$ & $(0.0106)$ \\
PIGS, Spatial Lag & -0.0006 & 0.0440 & 0.0345 \\
& $(0.0368)$ & $(0.0357)$ & $(0.0232)$ \\
\hline N & 70784 & 70716 & 70421 \\
State-Year FE & $\checkmark$ & $\checkmark$ & $\checkmark$ \\
Municipality FE & $\checkmark$ & $\checkmark$ & $\checkmark$ \\
Controls & $\checkmark$ & $\checkmark$ & $\checkmark$ \\
Control Functions & $\checkmark$ & $\checkmark$ & $\checkmark$ \\
\hline
\end{tabular}

Notes: Specification (1) reestimates the baseline model using the full sample. Specification (2) reestimates the baseline model excluding jurisdictions with a population in the top $0.1 \%$ of the distribution and specification (3) in the top $0.5 \%$. Bootstrapped standard errors in parentheses. $*, * *, * * *$ denote significance at the 10,5 and $1 \%$ level.

Finally note that one implication of the definition of the spatial lag variable is that the characteristics of multiple neighboring jurisdictions are subsumed in a onedimensional metric by taking weighted or unweighted averages. This implies that different changes in the vector of neighbors' policy choices are mapped into the same change in the spatial lag of the policy regressors. As an example, a 2 percentage point increase in a constructed unweighted average business tax rate of neighboring localities may in a scenario with 5 neighbors, reflect that one neighbor increased its local business tax by 10 percentage points or that all 5 neighbors raised their 
local business tax by 2 percentage points. The implicit assumption is that these policy changes have a comparable impact on firm foundations in the considered jurisdiction, which might be violated if cross-border effects were non-linear. We hence assessed the validity of this assumption by constructing measures for the fraction of neighboring localities, which experienced an increase in the local business tax rate (for each municipality and year). ${ }^{40}$ We interact this variable with the spatial lag of the local business tax rate. The coefficient estimate for this interaction term turns out small and statistically insignificant and the main findings remain unchanged. A similar picture emerges when we interact the spatial lag of the spending variable with the fraction of neighboring municipalities that encounter a PIGS increase and with the fraction of neighboring municipalities that encounter a PIGS decrease in a given year. This suggests that the sets of tax/PIGS reforms, which are subsumed in the same change of the spatial lag of the tax/PIGS regressor, indeed trigger comparable changes in new firm foundations.

\section{The effect of PIGS on family and transport intensive industries}

The analysis so far has been restricted to assessing the effect of the aggregate PIGS stock on the aggregate number of firm foundations per jurisdiction and year. The impact of PIGS on firm profits, enterpreneurs' wellbeing and, in consequence, firm foundation choices may, in turn, well differ across industries and across different types of PIGS. We test for this possibility based on two sets of consideration: Firstly, many PIGS provided by German municipalities are targeted at households and specifically at families with children. This, among others, concerns youth facilities, education, sports and recreation options, like playgrounds, parks, public swimming and public soccer courts. While it is individuals who directly benefit from these PIGS, firms may capture some of the related rents through lower wage costs (as

\footnotetext{
${ }^{40}$ Note that, within our sample period, a large number of municipalities increased their local business tax rates once of several times, while business tax declines were rare events.
} 
workers are willing to work for lower wages in areas with family-related amenities) or increased worker productivity. ${ }^{41}$ In the following, we will assess the effect of such 'family-PIGS' on the number of new firm foundations in 'family-intensive' industries. Theoretically, one might expect to see higher own-PIGS responses than in the baseline model as the considered firm pool is expected to be particularly strongly affected by the considered PIGS. In terms of PIGS spillover effects, predictions are ambiguous. On the one hand, one might expect to see higher positive spillover effects as commuting of enterpreneurs and workers might imply that municipalities close to residential communities with attractive family PIGS may become attractive firm locations. On the other hand, the busy time schedule of families may counteract this effect as parents may be reluctant to commute between communities. Moreover, the benefits of many family-PIGS, like schooling and childcare, exclusively accrue to households that reside in the PIGS-providing community, potentially further dampening the emergence of positive spillover effects. ${ }^{42}$

In the empirical analysis, 'family-PIGS' are defined as PIGS provision related to schools, recreations and sports, culture and public education, youth services and public transport. We, moreover, identify 'family-intensive' industries based on firmlevel information on the employment structures of all German establishments provided in the 'Establishment History Panel' of the Institute for Employment Research (IAB). Specifically, we use the waves for 1996 to 2007 to define 'family-intensity' according to the fraction of workers per firm, who are aged between 35 and 49 and are thus in the age range where individuals commonly live with children. ${ }^{43}$

Following this definition, Specifications (1) and (2) of Table 6 present the re-

\footnotetext{
${ }^{41}$ Alternatively, enterpreneurs may obtain direct benefits from PIGS provision and may for that reason be drawn to locate in communities with high levels of 'family-PIGS'.

${ }^{42}$ Families in Germany are e.g. only eligible to nursery places in their community of residence. Analogously, school choices tend to be restricted.

${ }^{43}$ The average age of birth giving mothers in Germany in 2018 was 31 years and the age of fathers was 34 years, see Table 12612-0006 and Table 12612-0007 on https://www-genesis.destatis.de/, the data portal of the Federal Statistical Office in Germany.
} 
sults of control function models where the dependent variable corresponds to the number of new firm foundations per community and year in family-intensive and non-family-intensive industries respectively, defined as 2-digit industries with an average fraction of 'family-aged' workers above and below the median respectively. Specifications (3) and (4) rerun the same specifications using as dependent variable the number of new firms in 2-digit industries with an average family-intensity above and below the 75 th percentile of the distribution respectively.

To avoid that our estimated 'family-PIGS' effect is confounded by - potentially correlated - PIGS provision in other dimensions, we subsume the PIGS stock related to communities' voluntary PIGS spending in other dimensions in one variable and include it as a control regressor in the indicated specifications. The family-related and other PIGS stock variables are thereby instrumented based on a shift-shareapproach (see Bartik (1991)), where the wind instrument is weighted by the fraction of the PIGS stock in the two PIGS categories relative to the overall PIGS stock in the pre-sample period 1997 in the first stage regressions.

The results suggest that family-related PIGS exert a significant and quantitatively large effect on the number of firm foundations in family-intensive industries, while the effects on firm foundations in non-family intensive industries are small and statistically insignificant. Specification (1) (Specification (3)) suggests that an increase in the stock of family-related PIGS by $1 \%$ (corresponding to an increase by 0.2 Mio Euros, on average) raises the number of firm foundations in industries with a family-intensity above the median (75th percentile of the distribution) by $1.2 \%$ $(2.3 \%)$. The coefficient estimate for the spatial lag of family-related PIGS (calculated based on neighbors within a $15 \mathrm{~km}$ distance radius and with inverse distance weights) moreover turns out negative and large in absolute size, suggesting strong beggar-thy-neighbor effects. The latter result contrasts our baseline findings, which 
suggested no significant PIGS spillover effects across borders. As sketched above, this may reflect a reluctance of parents to commute to work or capture that many family-PIGS can only be captured by households actually residing within community borders. Specifications (1)-(4) in Table B5 in the online appendix corroborate this evidence and show that similar results emerge when PIGS categories other than family-intensive PIGS are modelled in detail. ${ }^{44}$ Note, moreover, that, interestingly, we do not find significant differences in the response of family-intensive and nonfamily-intensive firms to changes in the local business tax rate, which indicates that the two type of firms do not differ in their general responsiveness to fiscal incentives.

As a second strategy, we assess the effect of the provision of public streets on the number of new firm foundations in transport intensive industries. The notion behind this sub-analysis is that transport-intensive firms are presumed to rely on a functioning road network and that PIGS investment in that dimension, in consequence, raise the attractiveness of municipalities as a location for firms in transport-intensive industries. In the following, we will use the average ratio of material inputs to sales as a proxy for the transport intensity of 2-digit-industries, calculated from firm accounts provided in Bureau van Dijk's DAFNE data. ${ }^{45}$

Specifications (5) to (8) of Table 6 report specifications where the number of new firm foundations in transport-intensive and non-transport-intensive industries respectively is regressed on the value of community streets (constructed based on the perpetual inventory method sketched in Section 3). In Specifications (5) and (7), the

\footnotetext{
${ }^{44}$ We again rely on a shift-share-strategy when implementing the control function approach. Note, moreover, that in the specifications of Table 7, the coefficient estimates for the spatial lag of the family-PIGS stock tend to be larger in quantitative terms than the coefficient estimates for the own effect of the family-PIGS stock. This asymmetry vanishes when the rest of the PIGS capital stock is modelled in more detail as in Table B5 of the online appendix. Note, moreover, that the estimates in Table B5 also suggest that firms in family-intensive sectors react more sensitively to the building and maintenance of community streets (which may relate to the fact that short-distances-mobility is important for families and a good infrastructure network reduces driving times within a locality).

${ }^{45}$ As firm coverage in DAFNE is rather poor prior to the mid 2000s, the transport intensity of firms is calculated based on data for the year 2009 .
} 
Table 6: Family and Transport Intensive Industries

\begin{tabular}{|c|c|c|c|c|c|c|c|c|}
\hline & \multicolumn{2}{|c|}{ Median } & \multicolumn{2}{|c|}{$\operatorname{Pctl}(75)$} & \multicolumn{2}{|c|}{ Median } & \multicolumn{2}{|c|}{$\operatorname{Pctl}(75)$} \\
\hline & \multicolumn{4}{|c|}{ Family Intensive Industries } & \multicolumn{4}{|c|}{ Transport Intensive Industries } \\
\hline & $\begin{array}{l}\text { Yes } \\
(1)\end{array}$ & $\begin{array}{l}\text { No } \\
(2)\end{array}$ & $\begin{array}{l}\text { Yes } \\
(3)\end{array}$ & $\begin{array}{l}\text { No } \\
(4)\end{array}$ & $\begin{array}{l}\text { Yes } \\
(5)\end{array}$ & $\begin{array}{l}\text { No } \\
(6)\end{array}$ & $\begin{array}{l}\text { Yes } \\
(7)\end{array}$ & $\begin{array}{l}\text { No } \\
(8)\end{array}$ \\
\hline LB Tax & $\begin{array}{l}-0.0120 \\
(0.0099)\end{array}$ & $\begin{array}{c}-0.0138^{* *} \\
(0.0059)\end{array}$ & $\begin{array}{c}-0.0092 \\
(0.0257)\end{array}$ & $\begin{array}{c}-0.0135^{* *} \\
(0.0059)\end{array}$ & $\begin{array}{c}-0.0162 * * * \\
(0.0041)\end{array}$ & $\begin{array}{l}-0.0140^{*} \\
(0.0079)\end{array}$ & $\begin{array}{c}-0.0177^{* * *} \\
(0.0066)\end{array}$ & $\begin{array}{c}-0.0142^{* * *} \\
(0.0049)\end{array}$ \\
\hline LB Tax, Spatial Lag & $\begin{array}{c}0.0115 \\
(0.0122)\end{array}$ & $\begin{array}{c}0.0176 * * * \\
(0.0068)\end{array}$ & $\begin{array}{c}0.0170 \\
(0.0330)\end{array}$ & $\begin{array}{c}0.0172^{* *} \\
(0.0072)\end{array}$ & $\begin{array}{c}0.0163 * * * \\
(0.0063)\end{array}$ & $\begin{array}{c}0.0164^{*} \\
(0.0087)\end{array}$ & $\begin{array}{c}0.0189^{* *} \\
(0.0080)\end{array}$ & $\begin{array}{c}0.0153^{* *} \\
(0.0071)\end{array}$ \\
\hline People PIGS & $\begin{array}{c}0.0575^{* * *} \\
(0.0205)\end{array}$ & $\begin{array}{c}0.0101 \\
(0.0113)\end{array}$ & $\begin{array}{l}0.1159 * * \\
(0.0517)\end{array}$ & $\begin{array}{c}0.0122 \\
(0.0116)\end{array}$ & & & & \\
\hline People PIGS, Spatial Lag & $\begin{array}{l}-0.0815^{*} \\
(0.0427)\end{array}$ & $\begin{array}{c}0.0490^{*} \\
(0.0272)\end{array}$ & $\begin{array}{c}-0.2884^{* * *} \\
(0.1062)\end{array}$ & $\begin{array}{l}0.0449^{*} \\
(0.0263)\end{array}$ & & & & \\
\hline Streets & & & & & $\begin{array}{c}0.0143 \\
(0.0094)\end{array}$ & $\begin{array}{c}0.0178 \\
(0.0110)\end{array}$ & $\begin{array}{c}0.0163 \\
(0.0118)\end{array}$ & $\begin{array}{c}0.0151 \\
(0.0107)\end{array}$ \\
\hline Streets, Spatial Lag & & & & & $\begin{array}{l}-0.0457 \\
(0.0441)\end{array}$ & $\begin{array}{c}0.0145 \\
(0.0539)\end{array}$ & $\begin{array}{l}-0.0352 \\
(0.0564)\end{array}$ & $\begin{array}{l}-0.0139 \\
(0.0564)\end{array}$ \\
\hline Other PIGS & $\begin{array}{c}0.0489 * * * \\
(0.0180)\end{array}$ & $\begin{array}{c}0.0135 \\
(0.0094)\end{array}$ & $\begin{array}{c}0.0987 * * \\
(0.0450)\end{array}$ & $\begin{array}{c}0.0154 \\
(0.0106)\end{array}$ & $\begin{array}{c}0.0177^{* *} \\
(0.0090)\end{array}$ & $\begin{array}{l}0.0212^{*} \\
(0.0113)\end{array}$ & $\begin{array}{l}0.0205^{*} \\
(0.0117)\end{array}$ & $\begin{array}{l}0.0191^{*} \\
(0.0103)\end{array}$ \\
\hline Other PIGS, Spatial Lag & $\begin{array}{c}-0.0486 \\
(0.0365)\end{array}$ & $\begin{array}{c}0.0273 \\
(0.0226)\end{array}$ & $\begin{array}{l}-0.1386 \\
(0.0955)\end{array}$ & $\begin{array}{c}0.0251 \\
(0.0246)\end{array}$ & $\begin{array}{l}-0.0116 \\
(0.0293)\end{array}$ & $\begin{array}{c}0.0278 \\
(0.0363)\end{array}$ & $\begin{array}{l}-0.0133 \\
(0.0344)\end{array}$ & $\begin{array}{c}0.0153 \\
(0.0352)\end{array}$ \\
\hline $\mathrm{N}$ & 54525 & 70254 & 34143 & 70522 & 68838 & 66344 & 63563 & 69517 \\
\hline Controls & $\checkmark$ & $\checkmark$ & $\checkmark$ & $\checkmark$ & $\checkmark$ & $\checkmark$ & $\checkmark$ & $\checkmark$ \\
\hline Municipality FEs & $\checkmark$ & $\checkmark$ & $\checkmark$ & $\checkmark$ & $\checkmark$ & $\checkmark$ & $\checkmark$ & $\checkmark$ \\
\hline State X Year FE & $\checkmark$ & $\checkmark$ & $\checkmark$ & $\checkmark$ & $\checkmark$ & $\checkmark$ & $\checkmark$ & $\checkmark$ \\
\hline Controls & $\checkmark$ & $\checkmark$ & $\checkmark$ & $\checkmark$ & $\checkmark$ & $\checkmark$ & $\checkmark$ & $\checkmark$ \\
\hline Control Functions & $\checkmark$ & $\checkmark$ & $\checkmark$ & $\checkmark$ & $\checkmark$ & $\checkmark$ & $\checkmark$ & $\checkmark$ \\
\hline \multicolumn{9}{|c|}{$\begin{array}{l}\text { Notes: The table presents model specifications, where the dependent variable is the number of new firms in (non-) family-intensive/(non- } \\
\text { )transport-intensive industries as defined in the main text. In Specifications (1) and (2), firms with a 'family-intensity' above and } \\
\text { below the median are counted, in Specifications }(3) \text { and }(4) \text {, firms with a family-intensity above and below the } 75 \text { th percentile of the } \\
\text { distribution. Analogously, in Specifications }(5) \text { and }(6) \text {, the dependent variable is the number of new firms with a transport-intensity } \\
\text { above and below the median, in Specifications }(7) \text { and }(8) \text {, firms with a transport-intensity above and below the } 75 \text { th percentile of the } \\
\text { distribution. The definition of the spatial lags of the regressors accounts for neighbors within } 15 \mathrm{~km} \text { distance and uses inverse distance } \\
\text { weights. The definition of the 'Streets' regressor corresponds to Section } 3 \text {, people goods comprise schools, recreations and sports, culture } \\
\text { and public education, youth services and public transport; other goods comprises all other categories described in Section } 3 \text {. Note that } \\
\text { the difference in the number of observations across specifications relates to communities, where the dependent variable takes on the value } \\
\text { zero for all sample years, so that the respective municipality is dropped from the sample. Bootstrapped standard errors in parentheses. } \\
*, * * * * \text { denote significance at the } 10,5 \text { and } 1 \% \text { level. }\end{array}$} \\
\hline
\end{tabular}

dependent variable is the number of new firm foundations per community and year in transport-intensive industries, defined as those with a ratio of material inputs over total sales above the median and the 75 th percentile of the distribution respectively. Inversely, in Specifications (6) and (8), the dependent variable is the number of firm foundations in non-transport intensive industries, defined as industries with material inputs relative to overall sales below the median and the 75 th percentile of the distribution respectively. Note, moreover, that the control function approach is again implemented based on the shift-share-strategy described above.

The coefficient estimates for the street regressor turn out small and statistically insignificant in all specifications, suggesting that community streets do not exert a significant impact on the emergence and attraction of new firms. We consider this finding to reflect that our analysis only captures expenditures related to the 
construction and maintenance of streets within a given municipality. Roads and highways that cross municipality borders, connect regions and have been shown by earlier research to impact firm behavior (see e.g. Moeller and Zierer (2018)), in turn, fall into the responsibility of higher government tiers. The insignificant effect of local street infrastructure on transport-intensive industries might, moreover, reflect that a major fraction of related public spending is assigned to the maintenance of existing roads instead of the construction of genuinely new infrastructure. Prior research suggests that, after the core infrastructure is built, firm benefits related to such 'marginal' investments tend to be limited (see e.g. Fernald (1999)). For the sake of completeness, furthermore note that the tax effects on the emergence of new firms are again quantitatively similar to our baseline estimates for both subgroups of firms.

\section{External validity}

Finally, as our sample period ends a decade ago in 2006, one might have concerns that firms' policy responsiveness may have changed in between and our results may not be suited to guide today's policy. ${ }^{46}$ To assess this possibility, we firstly determined whether the businesses' policy responsiveness changed within our sample frame. If that was not the case, one may have some confidence that effect size has been also been stable after the end of the sample frame. While our instrumental variable strategy does not allow us to test this notion in the PIGS dimension (since changes in municipalities' PIGS provision are identified through the RES Act in 2000), variation in the reference tax instrument allows for an according test in the business tax dimension. The results are presented in Specification (1) of Table 7 and show no significant change in the business tax effect within our sample frame. Note, moreover, that - in line with this finding - presumed determinants of the

\footnotetext{
${ }^{46}$ As sketched in Section III, German local PIGS data is not comparable before 2006 and 2007 as German localities changed their accounting system.
} 
link between local policies and firm foundations tend to be rather time-persistent. Agglomeration characteristics and industry structures, for example, do not change within a couple of years. Specifications (2) and (3) of Table 7, moreover, show that the effect of local policies on firm foundations does not significantly differ between service and non-service firms in our sample.

Data from the German company register, however, suggests two interesting developments in our post sample period: The share of newly founded firms as a percentage of municipalities' aggregate firm number decreased in the post sample frame and, simultaneously, newly founded firm became larger. While, on average, newly founded firms employed around two workers in 2008, they employed around 2.5 workers ten years later (see Figure 5). According to evidence in Becker et al. (2012) and Riedel and Simmler (2018), larger firms tend to be more mobile and more responsive to policy changes than smaller firms; this suggests that our estimates might be a lower bound for today's corporate policy responsiveness.

Table 7: External Validity

\begin{tabular}{lccc}
\hline Sample & $\begin{array}{c}\text { All } \\
(1)\end{array}$ & $\begin{array}{c}\text { Service } \\
(2)\end{array}$ & $\begin{array}{c}\text { Non-Service } \\
(3)\end{array}$ \\
\hline LB Tax & -0.0059 & $-0.0207^{* *}$ & $-0.0126^{* *}$ \\
& $(0.0038)$ & $(0.0082)$ & $(0.0054)$ \\
LB Tax * Trend & -0.0002 & & \\
& $(0.0003)$ & & \\
LB Tax, Spatial Lag & $0.0097^{*}$ & $0.0222^{* *}$ & $0.0186^{* * *}$ \\
& $(0.0052)$ & $(0.0095)$ & $(0.0065)$ \\
LB Tax, Spatial Lag * Trend & 0.0006 & & \\
& $(0.0004)$ & & \\
PIGS & $0.0292^{* * *}$ & 0.0220 & $0.0261^{* * *}$ \\
& $(0.0092)$ & $(0.0144)$ & $(0.0081)$ \\
PIGS, Spatial Lag & 0.0428 & 0.0133 & 0.0371 \\
& $(0.0273)$ & $(0.0368)$ & $(0.0305)$ \\
\hline N & 70653 & 70653 & 70653 \\
State-Year FE & $\checkmark$ & $\checkmark$ & $\checkmark$ \\
Municipality FE & $\checkmark$ & $\checkmark$ & $\checkmark$ \\
Controls & $\checkmark$ & $\checkmark$ & $\checkmark$ \\
Control Functions & $\checkmark$ & $\checkmark$ & $\checkmark$ \\
\hline Notes: Specification (1) includes an interaction between the tax and \\
the spatial lag of the tax with a trend variable. In Specifications (2) \\
and (3), the sample is restricted to service and non-service firms respec- \\
tively. Bootstrapped standard errors in parentheses. *,***** denote \\
significance at the 10, 5 and 1\% level. \\
(2)
\end{tabular}


Figure 5: Evolution Share of New Firms and Worker per New Firms 2008 to 2017

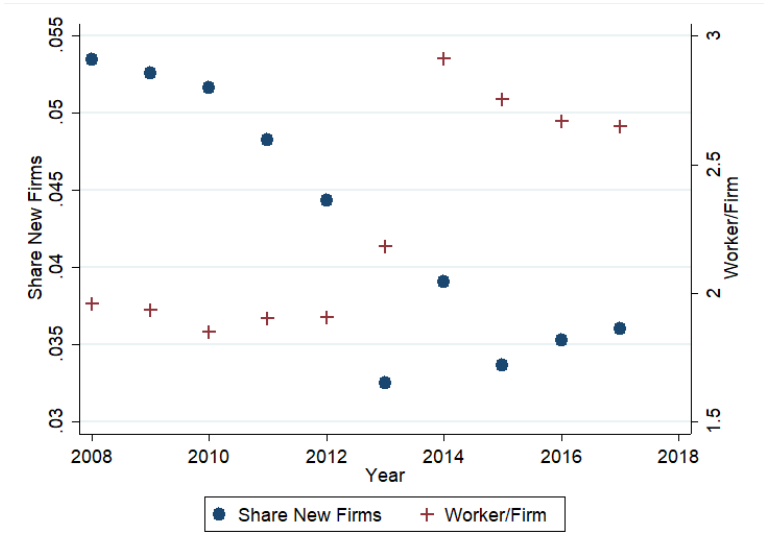

Notes: The figures depict the share of new firms as well as the average number of workers per new firm using data from the company register in Germany. The number of new firms includes only new firms with at least one employee that is subject to social security contributions.

\section{Conclusion}

In this paper, we estimated the effect of local business taxes and local PIGS provision on the number and spatial distribution of new firms. Using Germany as a testing ground and estimating fixed effects Poisson regressions coupled with a control function approach, we find that both, local business taxes and PIGS provision exert a quantitatively significant impact on the number of new firm foundations in the policy-changing jurisdiction. The findings hence suggest that local fiscal policies do change firm behaviour. Our results, moreover, point to beggar-thy-neighbor externalities: Reductions in local business tax rates are found to strongly lower the number of news firms in neighboring communities, implying that the aggregate number of firms remains unchanged. Analogous beggar-thy-neighbor externalities emerge in the PIGS dimension - for subsets of firms and PIGS. Evidence on such spillovers supports theory models, where fiscal interactions between local governments root in firm mobility across borders. Complemented by information on the sign and size of fiscal interactions, this adds to our understanding of the optimal size and structure of local government activities. 


\section{REFERENCES}

Albouy, D. and LuE, B. (2015). Driving to opportunity: Local rents, wages, commuting, and sub-metropolitan quality of life. Journal of Urban Economics, 89, $74-92$.

Arauzo-Carod, J.-M. and Manjón-Antolín, M. (2012). (Optimal) spatial aggregation in the determinants of industrial location. Small Business Economics, 39 (3), 645-658.

BARTIK, T. J. (1991). Who benefits from state and local economic development policies? Kalamazoo, MI: W.E. Upjohn Institute for Employment Research.

Baskaran, T. and Hessami, Z. (2014). Political alignment and intergovernmental transfers in parliamentary systems: Evidence from Germany. Working Paper Series of the Department of Economics, University of Konstanz 2014-17, Department of Economics, University of Konstanz.

Becker, S., Egger, P. and Merlo, V. (2012). How low business tax rates attract mne activity: Municipality-level evidence from germany. Journal of Public Economics, 96 (9-10), 698-711.

Bénassy-Quéré, A., Gobalraja, N. and Trannoy, A. (2007). Tax and public input competition. Economic Policy, 22 (50), 386-430.

Brülhart, M., Jametti, M. and Schmidheiny, K. (2012). Do agglomeration economies reduce the sensitivity of firm location to tax differentials? The Economic Journal, 122 (563), 1069-1093.

Buettner, T. and Holm-Hadulla, F. (2008). Fiscal equalization: The case of german municipalities. CESifo DICE Report, 1-2008, 16-20.

- and JANEBA, E. (2016). City competition for the creative class. Journal of Cultural Economics, 40 (4), 413-451.

Cameron, A. and Trivedi, P. (2005). Microeconometrics: Methods and Applications. Cambridge University Press.

Chirinko, R. and Wilson, D. (2017). Tax competition among u.s. states: Racing to the bottom or riding on a seesaw? Journal of Public Economics, 155, $147-163$.

DeMooji, R. and Ederveen, S. (2003). Taxation and foreign direct investment: A synthesis of empirical research. International Tax and Public Finance, 10 (6), 673-693.

Deuchert, E. and Huber, M. (2017). A cautionary tale about control variables in iv estimation. Oxford Bulletin of Economics and Statistics, 79 (3), 411-425. 
Devereux, M., Lockwood, B. and Redoano, M. (2008). Do countries compete over corporate tax rates? Journal of Public Economics, 92, 1210-1235.

DonalDSON, D. (2018). Railroads of the raj: Estimating the impact of transportation infrastructure. American Economic Review, 108 (4-5), 899?934.

Duflo, E. and Pande, R. (2007). Dams. Quarterly Journal of Economics, $122(2), 601-646$.

Feld, L. and Heckemeyer, J. (2011). Fdi and taxation: A meta-study. Journal of Economic Surveys, 25 (2), 233-272.

Fernald, G. (1999). Roads to prosperity? assessing the link between public capital and productivity. American Economic Review, 89 (3), 619-638.

ForBes (2017). The best small cities for business and career 2017. November 6, $201 \%$.

Foremny, D. and Riedel, N. (2014). Business taxes and the electoral cycle. Journal of Public Economics, 115 (C), 48-61.

Freier, R. and Odendahl, C. (2015). Do parties matter? estimating the effect of political power in multi-party systems. European Economic Review, 80, $310-328$.

Gabe, T. M. and Bell, K. P. (2004). Tradeoffs between local taxes and government spending as determinants of business location. Journal of Regional Science, 44 (1), 21-41.

Giroud, X. and Rauh, J. (2017). State taxation and the reallocation of business activity: Evidence from establishment-level data. mimeo, Stanford Graduate School of Business.

Guimarães, P., Figueirdo, O. and Woodward, D. (2003). A tractable approach to the firm location decision problem. Review of Economics and Statistics, 85 (1), 201-204.

Habermann, H. and Breustedt, G. (2011). Einfluss der Biogaserzeugung auf landwirtschaftliche Pachtpreise in Deutschland. German Journal of Agricultural Economics, 60 (2), 85-100.

Hauptmeier, S., Mittermaier, F. and Rincke, J. (2012). Fiscal competition over taxes and public inputs. Regional Science and Urban Economics, 42 (3), 407 - 419, special Section on Asian Real Estate Market.

Holl, A. (2004). Transport infrastructure, agglomeration economies, and firm birth: Empirical evidence from portugal. Journal of Regional Science, 44 (4), 693-712. 
Hopp, D. and Kriebel, M. (2019). The political economy of interregional competition for firms. Regional Science and Urban Economics, forthcoming.

IHK (2016). Reform des kommunalen Finanzausgleichs verursacht Steuererhoehungen. Pressemitteilung, Februar 5, 2016.

Jackson, C. K., Johnson, R. C. and Persicoe, C. (2016). The effects of school spending on educational and economic outcomes: Evidence from school finance reforms. Quarterly Journal of Economics, 131 (1), 157-218.

Keen, M. and Konrad, K. A. (2013). The Theory of International Tax Competition and Coordination, Handbook of Public Economics Volume 5, North Holland: Elsevier, p. Chapter 5.

KoH, H.-J., Riedel, N. and BöHm, T. (2013). Do governments tax agglomeration rents? Journal of Urban Economics, 75 (Supplement C), 92 106.

Krogstrup, S. and Wyplosz, C. (2006). A common pool theory of deficit bias correction. mimeo, Graduate Institute of International Studies, Geneva.

Langenmayr, D. and Simmler, M. (2018). Why the current tax rate tells you little: Competing for mobile and immobile firms. CESifo Working Paper, 6827.

LeSage, J., Baneruee, S., Fischer, M. M. and Congdon, P. (2009). Spatial statistics: Methods, models \& computation. Computational Statistics \& Data Analysis, 53 (8), 2781 - 2785.

Moeller, J. and Zierer, M. (2018). Autobahns and jobs: A regional study using historical instrumental variables. Journal of Urban Economics, 103, 18-33.

Neumark, D. and Simpson, H. (2015). Place-Based Policie, Handbook of Regional and Urban Economics Volume 5, Elsevier, pp. 1197-1287.

PARChEt, R. (2019). Are local tax rates strategic complements or strategic substitutes? American Economic Journal: Economic Policy, 11(2), 41-51.

Ratts $\varnothing$, J. (2004). Fiscal adjustment under centralized federalism: Empirical evaluation of the response to budgetary shocks. FinanzArchiv, 60(2), 240-261.

Riedel, N. and Simmler, M. (2018). Large and influential: Firm size and governments' corporate tax rate choice. CESifo Working Paper Series, No. 690.

- , - and Wittrock, C. (2018). Local fiscal policies and their impact on the number and spatial distribution of new firms. Oxford University Centre for Business Taxation, Working Paper 18/20. 
Ries, J. and Somerville, T. (2010). School quality and residential property values: Evidence from vancouver rezoning. The Review of Economics and Statistics, 92 (4), 928-944.

Siggelkow, B. F. (2018). Tax competition and the implications of national tax policy coordination in the presence of fiscal federalism. Regional Science and Urban Economics, 73, 17-29.

SOlÉ-Ollé, A. (2006). Expenditure spillovers and fiscal interactions: Empirical evidence from local governments in spain. Journal of Urban Economics, 59 (1), $32-53$.

Sonoran Institute (2015). Place Value: How Communities Attract, Grow and Keep Jobs and Talent in the Rocky Mountain West. Tech. rep.

SuÁrez Serrato, J. C. and Zidar, O. (2016). Who benefits from state corporate tax cuts? a local labor markets approach with heterogeneous firms. American Economic Review, 106 (9), 2582-2624.

Tabellini, G. and Alesina, A. (1990). Voting on the budget deficit. American Economic Review, 80, 37-49.

UK Government - Department for Business, Energy and Industrial StRATEGy (2019). Drivers of firm relocation: Final report. BEIS Research Paper, No. 2019/002.

U.S. Chamber of Commerce Foundation (2016). Innovation that matters 2015. U.S. Chamber of Commerce, Free Entreprise, 1776.

Winner, H. (2012). Fiscal competition and the composition of public expenditure: An empirical study. Contemporary Economics, 6.

Wittrock, C. (2018). Firm foundation and localization economies - the sensitivity to taxation and the provision of public goods. University of Dortmund, Working Paper.

Wooldridge, J. (2010). Econometric Analysis of Cross Section and Panel Data. Econometric Analysis of Cross Section and Panel Data, MIT Press. 


\section{Appendix A: Proofs for Theoretical Model}

Proof of Lemma 1. Under the assumption that $m(1)$ is sufficiently high,

$$
\Delta(0)=\left(t_{2}-t_{1}\right) V+\left(\left(1-t_{1}\right) B_{1}\left(c_{1}, c_{2}\right)-\left(1-t_{2}\right) B_{2}\left(c_{1}, c_{2}\right)\right)+m(1)-m(0)>0
$$

and

$$
\Delta(1)=\left(t_{2}-t_{1}\right) V+\left(\left(1-t_{1}\right) B_{1}\left(c_{1}, c_{2}\right)-\left(1-t_{2}\right) B_{2}\left(c_{1}, c_{2}\right)\right)+m(0)-m(1)<0 .
$$

By the intermediate value theorem, there exists $\bar{x}$ with $\Delta(\bar{x})=0$. Because

$$
\frac{\partial \Delta(x)}{\partial x}=-\left(m^{\prime}(x)+m^{\prime}(1-x)\right)<0,
$$

$\Delta(x)$ is monotone and thus $\bar{x}$ is unique and $\Delta(x)>0$ if $x<\bar{x}$ and $\Delta(x)<0$ if $x>\bar{x}$.

Proof of Lemma 2. $\bar{x}$ is implicitly defined by $\Delta(\bar{x})=0$. By the implicit function theorem, it is sufficient to consider $\partial \Delta(x) / \partial p$ for $p \in\left\{t_{1}, t_{2}, c_{1}, c_{2}\right\}$.

1. For the first part of Lemma 2, consider

$$
\begin{aligned}
& \frac{\partial \Delta(x)}{\partial t_{1}}=-\left(V+B_{1}\left(c_{1}, c_{2}\right)\right)<0, \\
& \frac{\partial \Delta(x)}{\partial t_{2}}=\left(V+B_{2}\left(c_{1}, c_{2}\right)\right)>0,
\end{aligned}
$$

where the signs follow from

$$
\left(V+B_{j}\left(c_{1}, c_{2}\right)\right)>0
$$

given an optimal location and entry choice.

2. For the second part of the lemma, consider

$$
\begin{array}{ll}
\frac{\partial \Delta(x)}{\partial c_{1}}= & \left(1-t_{1}\right) \frac{\partial B_{1}}{\partial c_{1}}-\left(1-t_{2}\right) \frac{\partial B_{2}}{\partial c_{1}}>0 \text { if }\left(1-t_{1}\right) \frac{\partial B_{1}}{\partial c_{1}}>\left(1-t_{2}\right) \frac{\partial B_{2}}{\partial c_{1}} \\
\frac{\partial \Delta(x)}{\partial c_{2}}= & \left(1-t_{1}\right) \frac{\partial B_{1}}{\partial c_{2}}-\left(1-t_{2}\right) \frac{\partial B_{2}}{\partial c_{2}}>0 \text { if }\left(1-t_{1}\right) \frac{\partial B_{1}}{\partial c_{2}}>\left(1-t_{2}\right) \frac{\partial B_{2}}{\partial c_{2}}
\end{array}
$$

as stated in Lemma 2 . 


\section{Appendix B: Additional Figures and Estimation Results}

Figure B1: Distribution of the Local Business Tax - NRW

Figure B1 (a): Distribution of the Local Business Tax in 1998

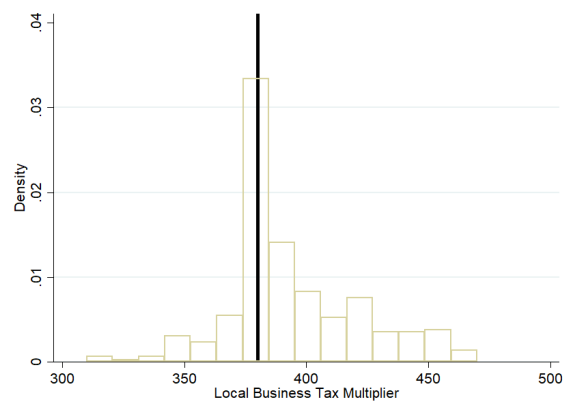

Figure B1 (b): Distribution of the Local Business Tax in 2006

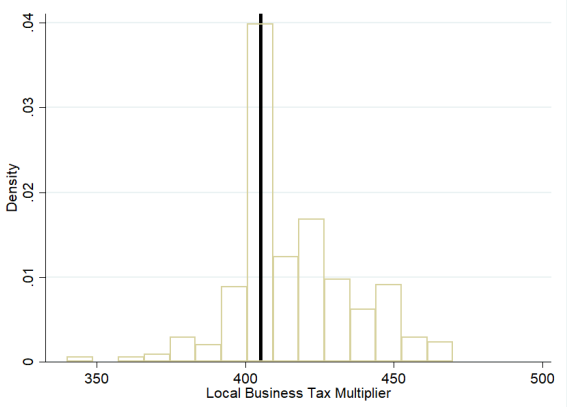

Notes: Figure B1 (a) depicts the distribution of the local business tax in 1998 for communities in the state of North Rhine Westfalia. Figure B1 (b) depicts the distribution of the local business tax in 2006 in North Rhine Westfalia. In both cases, the black line indicates the reference tax in the fiscal equalization scheme. 
Table B2: First Stage Results, Control Function Approach

\begin{tabular}{|c|c|c|c|c|}
\hline & (1) & $(2)$ & (3) & (4) \\
\hline & \multicolumn{4}{|c|}{ First Stage - Dependent Variable: Local Business Tax } \\
\hline Reference Tax Dummy & \multirow{6}{*}{$\begin{array}{c}10.7563^{* * *} \\
(0.7918)\end{array}$} & & \multirow{6}{*}{$\begin{array}{c}10.6709^{* * *} \\
(0.7886) \\
-0.0034^{* * *} \\
(0.0011) \\
-0.0007^{*} \\
(0.0004)\end{array}$} & $\begin{array}{c}8.6476^{* * *} \\
(0.7792)\end{array}$ \\
\hline Wind $\mathrm{x}$ AGR $\mathrm{x}$ Reform & & & & $\begin{array}{l}-0.00414 \\
(0.0013)\end{array}$ \\
\hline Wind $x$ AGR $x$ Reform $x$ Trend & & & & -0.0002 \\
\hline Reference Tax Dummy, Spatial Lag & & & & $\begin{array}{c}18.7990^{* * *} \\
(1.8894)\end{array}$ \\
\hline Wind x AGR x Reform, Spatial Lag & & & & $\begin{array}{c}-0.0070^{* * *} \\
(0.0024)\end{array}$ \\
\hline \multirow[t]{2}{*}{ Wind $x$ AGR x Reform x Trend, Spat. Lag } & & & & $\begin{array}{c}-0.0016^{* *} \\
(0.0008)\end{array}$ \\
\hline & \multicolumn{4}{|c|}{ First Stage - Dependent Variable: PIGS Capital Stock } \\
\hline Reference Tax Dummy & & & \multirow{6}{*}{$\begin{array}{c}0.1166 \\
(0.2615) \\
0.0057^{* * *} \\
(0.0008) \\
0.0003 \\
(0.0002)\end{array}$} & $\begin{array}{c}0.1377 \\
(0.2669)\end{array}$ \\
\hline Wind $x$ AGR $x$ Reform & & $\begin{array}{c}0.0057^{* * *} \\
(0.0008)\end{array}$ & & $\begin{array}{c}0.0063^{* * *} \\
(0.0010)\end{array}$ \\
\hline Wind $x$ AGR $x$ Reform $x$ Trend & & $\begin{array}{c}0.0003 \\
(0.0002)\end{array}$ & & $\begin{array}{c}0.0005^{* *} \\
(0.0003)\end{array}$ \\
\hline Reference Tax Dummy, Spatial Lag & & & & $\begin{array}{c}-2.7488 * * * \\
(0.6574)\end{array}$ \\
\hline Wind x AGR x Reform, Spatial Lag & & & & $\begin{array}{c}-0.0024^{* *} \\
(0.0012)\end{array}$ \\
\hline \multirow[t]{2}{*}{ Wind $x$ AGR x Reform x Trend, Spat. Lag } & & & & $\begin{array}{c}-0.0009^{* *} \\
(0.0004)\end{array}$ \\
\hline & \multicolumn{4}{|c|}{ First Stage - Dependent Variable: Local Business Tax, Spatial Lag } \\
\hline \multicolumn{4}{|l|}{ Reference Tax Dummy } & $\begin{array}{l}1.8179^{* * *} \\
(0.3563)\end{array}$ \\
\hline Wind $x$ AGR $x$ Reform & & & & $\begin{array}{l}-0.0004 \\
(0.0007)\end{array}$ \\
\hline Wind $x$ AGR $x$ Reform $x$ Trend & & & & $\begin{array}{l}-0.0003 \\
(0.0003)\end{array}$ \\
\hline Reference Tax Dummy, Spatial Lag & & & & $\begin{array}{l}22.9233 * * * \\
(1.1752)\end{array}$ \\
\hline Wind x AGR x Reform, Spatial Lag & & & & $\begin{array}{c}-0.0074 * * * \\
(0.0011)\end{array}$ \\
\hline \multirow[t]{2}{*}{ Wind x AGR x Reform x Trend, Spat. Lag } & & & & $\begin{array}{c}-0.0012^{* * *} \\
(0.0004)\end{array}$ \\
\hline & First Stage - & Dependent & riable: PIGS & Stock, Spatial Lag \\
\hline Reference Tax Dummy & & & & $\begin{array}{l}-0.1767 \\
(0.1558)\end{array}$ \\
\hline Wind $x$ AGR $x$ Reform & & & & $\begin{array}{c}-0.0006 * * * \\
(0.0002)\end{array}$ \\
\hline Wind $x$ AGR x Reform x Trend & & & & $\begin{array}{l}0.0000 \\
(0.0000)\end{array}$ \\
\hline Reference Tax Dummy, Spatial Lag & & & & $\begin{array}{c}-1.1876 * * * \\
(0.4199)\end{array}$ \\
\hline Wind x AGR x Reform, Spatial Lag & & & & $\begin{array}{c}0.0041^{* * *} \\
(0.0005)\end{array}$ \\
\hline Wind x AGR x Reform x Trend, Spat. Lag & & & & $\begin{array}{c}-0.0009^{* * *} \\
(0.0003) \\
\end{array}$ \\
\hline $\mathrm{N}$ & 70653 & 70653 & 70653 & 70653 \\
\hline Municipality FE & $\checkmark$ & $\checkmark$ & $\checkmark$ & $\checkmark$ \\
\hline State X Year FE & $\checkmark$ & $\checkmark$ & $\checkmark$ & $\checkmark$ \\
\hline Control Variables & $\checkmark$ & $\checkmark$ & $\checkmark$ & $\checkmark$ \\
\hline $\begin{array}{l}\text { Notes: The table presents first stage regres } \\
\text { the first stage models that corresponds to t } \\
\text { depicts the first stage models that correspon } \\
\text { on. 'Reference Tax Dummy' is a dummy va } \\
\text { scheme is larger or smaller than the comm } \\
\text { 'Wind x AGR x Reform x Trend' capture } \\
\text { described in Section IV; 'Reform' is a dumn } \\
\text { is a variable that takes on the value } 0 \text { in th } \\
2001,2002,2003 \text { etc..). }\end{array}$ & $\begin{array}{l}\text { ions for our } \\
\text { e second stag } \\
\text { ls to the secor } \\
\text { iable indicati } \\
\text { nity's local b } \\
\text { he communit } \\
\text { y variable wh } \\
\text { reform year }\end{array}$ & $\begin{array}{l}\text { aseline con } \\
\text { model pres } \\
\text { d stage mod } \\
\text { g whether t } \\
\text { isiness tax } \\
\text { es' exposur } \\
\text { ch takes on } \\
000 \text { and val }\end{array}$ & $\begin{array}{l}1 \text { function ap } \\
\text { ted in Colum } \\
\text { presented in } \\
\text { reference ta: } \\
\text { te in } 1998 \text {. } \\
\text { o wind and } \\
\text { e value } 1 \text { for } \\
1,2,3 \text { and }\end{array}$ & $\begin{array}{l}\text { Column (1) depicts } \\
\text { Table 2, Column (2) } \\
\text { (2) of Table } 2 \text { and so } \\
\text { he fiscal equalization } \\
\text { AGR x Reform' and } \\
\text { agricultural space as } \\
\text { fter } 2000 \text { and 'Trend' } \\
\text { or the following years }\end{array}$ \\
\hline
\end{tabular}




\section{Table B3: Conditional Correlation Control Variables and Instruments}

\begin{tabular}{|c|c|c|}
\hline & Population & Unemployment \\
\hline Reference Tax Dummy & $\begin{array}{l}0.0530^{*} \\
(0.0281)\end{array}$ & $\begin{array}{l}-0.0621 \\
(0.0445)\end{array}$ \\
\hline Wind $x$ AGR $x$ Reform & $\begin{array}{c}0.0004^{* * *} \\
(0.0000)\end{array}$ & $\begin{array}{l}-0.0002^{*} \\
(0.0001)\end{array}$ \\
\hline Wind $x$ AGR $x$ Reform $x$ Trend & $\begin{array}{c}0.0001^{* * *} \\
(0.0000)\end{array}$ & $\begin{array}{l}0.0001^{* *} \\
(0.0000)\end{array}$ \\
\hline $\mathrm{N}$ & 70653 & 70653 \\
\hline Municipality FE & $\checkmark$ & $\checkmark$ \\
\hline State X Year FE & $\checkmark$ & $\checkmark$ \\
\hline
\end{tabular}

Table B4: Sensitivity Control Function Approach II

\begin{tabular}{lcccccc}
\hline PIGS Instrument & \multicolumn{5}{c}{ Wind X Agr } & Corn \\
\cline { 2 - 6 } \cline { 3 - 6 } & $(1)$ & $(2)$ & $(3)$ & $(4)$ & $(5)$ & $(6)$ \\
\hline LB Tax & $-0.0145^{* * *}$ & $-0.0116^{* *}$ & $-0.0137^{* * *}$ & $-0.0118^{* *}$ & $-0.0119^{* *}$ & $-0.0127^{* *}$ \\
& $(0.0046)$ & $(0.0049)$ & $(0.0051)$ & $(0.0047)$ & $(0.0050)$ & $(0.0059)$ \\
LB Tax, Spatial Lag & $0.0152^{* * *}$ & $0.0139^{* * *}$ & $0.0146^{* *}$ & $0.0142^{* *}$ & $0.0132^{* *}$ & $0.0114^{* *}$ \\
& $(0.0057)$ & $(0.0044)$ & $(0.0063)$ & $(0.0056)$ & $(0.0064)$ & $(0.0062)$ \\
PIGS & $0.0288^{* *}$ & 0.0142 & $0.0315^{* *}$ & $0.0222^{* *}$ & $0.0251^{* *}$ & 0.0310 \\
& $(0.0113)$ & $(0.0179)$ & $(0.126)$ & $(0.0097)$ & $(0.099)$ & $(0.0356)$ \\
PIGS, Spatial Lag & -0.0455 & 0.0580 & -0.0329 & -0.0277 & -0.0425 & -0.0764 \\
& $(0.0389)$ & $(0.0394)$ & $(0.0309)$ & $(0.0233)$ & $(0.0317)$ & $(0.0509)$ \\
\hline N & 61054 & 61054 & 61054 & 61054 & 61054 & 61054 \\
State-Year FE & $\checkmark$ & $\checkmark$ & $\checkmark$ & $\checkmark$ & $\checkmark$ & $\checkmark$ \\
Municipality FE & $\checkmark$ & $\checkmark$ & $\checkmark$ & $\checkmark$ & $\checkmark$ & $\checkmark$ \\
Controls & $\checkmark$ & $\checkmark$ & $\checkmark$ & $\checkmark$ & $\checkmark$ & $\checkmark$ \\
Control Functions & $\checkmark$ & $\checkmark$ & $\checkmark$ & $\checkmark$ & $\checkmark$ & $\checkmark$ \\
Correction Built & & & & Yes & Yes & \\
Wind Turbines & & $\checkmark$ & & $($ less 1$)$ & $(1 \mathrm{ess} \#)$ & \\
Commuting-Year FE & & & $\checkmark$ & & & \\
Partisan Controls & & & & & \\
\hline
\end{tabular}

Notes: In all specifications, the sample exclude the states of Baden-Württemberg and Saarland due to data availability (see text). Specification (1) reestimates the baseline model. In specification (2) we account for commuting-year instead of state-year fixed effects and in specification (3) we additionally include the seat share of the political parties in the community council. In specification (4), we report the results for analogous model specifications, where the dependent variable is the number of new establishments per municipality and year minus 1 if at least one new wind turbine has been erected in the respective community in a particular year. In specification (5), the analogous model is estimated with a dependent variable which is the number of new establishments per municipality and year minus the actual number of wind turbines built in a jurisdiction and given year. In specification (6), we instrument community spending with communities' capacity for corn production instead of wind strength and agricultural space. Bootstrapped standard errors in parentheses. ${ }^{*},{ }^{* *},{ }^{* * *}$ denote significance at the 10,5 and $1 \%$ level. 
Table B5: Family and Transport Intensive Industries

\begin{tabular}{|c|c|c|c|c|c|c|c|c|}
\hline & \multicolumn{2}{|c|}{ Median } & \multicolumn{2}{|c|}{$\operatorname{Pctl}(75)$} & \multicolumn{2}{|c|}{ Median } & \multicolumn{2}{|c|}{$\operatorname{Pctl}(75)$} \\
\hline & \multicolumn{4}{|c|}{ Family Intensive Industries } & \multicolumn{4}{|c|}{ Transport Intensive Industries } \\
\hline & $\begin{array}{l}\text { Yes } \\
\text { (1) }\end{array}$ & $\begin{array}{l}\text { No } \\
(2)\end{array}$ & $\begin{array}{l}\text { Yes } \\
(3)\end{array}$ & $\begin{array}{l}\text { No } \\
\text { (4) }\end{array}$ & $\begin{array}{l}\text { Yes } \\
(5)\end{array}$ & $\begin{array}{l}\text { No } \\
(6)\end{array}$ & $\begin{array}{l}\text { Yes } \\
(7)\end{array}$ & $\begin{array}{l}\text { No } \\
(8)\end{array}$ \\
\hline \multirow[t]{2}{*}{ LB Tax } & $-0.0164^{*}$ & $-0.0134^{* *}$ & -0.0262 & $-0.0132 * *$ & $-0.0150^{* * *}$ & -0.0119 & $-0.0169 * * *$ & $-0.0122^{* * *}$ \\
\hline & 0.0096 & 0.0054 & 0.0244 & 0.0054 & 0.0038 & 0.0073 & 0.0065 & 0.0046 \\
\hline \multirow[t]{2}{*}{ LB Tax, Spatial Lag } & 0.0156 & $0.0179^{* * *}$ & 0.0489 & $0.0172 * *$ & $0.0186 * * *$ & $0.0161 * *$ & $0.0209^{* *}$ & $0.0163^{* * *}$ \\
\hline & 0.0136 & 0.0068 & 0.0306 & 0.0073 & 0.0062 & 0.0079 & 0.0083 & 0.0059 \\
\hline \multirow[t]{2}{*}{ People PIGS } & $0.0611^{* *}$ & -0.0071 & $0.1512^{* *}$ & -0.0044 & 0.0052 & -0.0069 & 0.0185 & -0.0087 \\
\hline & 0.0288 & 0.0169 & 0.0604 & 0.0195 & 0.0133 & 0.0165 & 0.0193 & 0.0185 \\
\hline \multirow[t]{2}{*}{ People PIGS, Spatial Lag } & -0.0487 & 0.0109 & $-0.1785^{* *}$ & 0.0100 & -0.0037 & 0.0088 & -0.0145 & 0.0116 \\
\hline & 0.0447 & 0.0273 & 0.0762 & 0.0303 & 0.0234 & 0.0284 & 0.0276 & 0.0287 \\
\hline \multirow[t]{2}{*}{ Streets } & $0.0481^{* *}$ & 0.0014 & $0.1140^{* *}$ & 0.0035 & 0.0102 & 0.0019 & 0.0181 & 0.0012 \\
\hline & 0.0236 & 0.0135 & 0.0507 & 0.0158 & 0.0106 & 0.0137 & 0.0157 & 0.0142 \\
\hline \multirow{2}{*}{ Streets, Spatial Lag } & -0.0550 & 0.0063 & $-0.1484 * *$ & 0.0052 & -0.0173 & 0.0176 & -0.0256 & 0.0113 \\
\hline & 0.0424 & 0.0237 & 0.0739 & 0.0273 & 0.0208 & 0.0263 & 0.0242 & 0.0228 \\
\hline \multirow[t]{2}{*}{ Economic Promotion } & -0.1330 & 0.1435 & -0.4632 & 0.1376 & 0.0837 & $0.1630^{*}$ & 0.0019 & $0.1756^{*}$ \\
\hline & 0.1380 & 0.0882 & 0.2934 & 0.0899 & 0.0703 & 0.0888 & 0.0839 & 0.1014 \\
\hline \multirow[t]{2}{*}{ Economic Promotion, Spatial Lag } & 0.1334 & 0.0072 & $1.1582^{*}$ & -0.0042 & -0.0197 & 0.0922 & 0.0317 & 0.0243 \\
\hline & 0.3349 & 0.1722 & 0.6538 & 0.1730 & 0.1556 & 0.2002 & 0.1935 & 0.1929 \\
\hline \multirow{2}{*}{ Other PIGS } & 0.1165 & -0.0581 & 0.2859 & -0.0524 & -0.0242 & -0.0638 & 0.0187 & -0.0707 \\
\hline & 0.0997 & 0.0665 & 0.2350 & 0.0620 & 0.0536 & 0.0696 & 0.0563 & 0.0748 \\
\hline \multirow[t]{2}{*}{ Other PIGS, Spatial Lag } & -0.0631 & 0.1538 & -0.0561 & 0.1419 & 0.0912 & 0.1673 & 0.0382 & 0.1791 \\
\hline & 0.1780 & 0.1114 & 0.3617 & 0.1175 & 0.1175 & 0.1133 & 0.1350 & 0.1137 \\
\hline $\mathrm{N}$ & 54525 & 70254 & 34143 & 70522 & 68838 & 66344 & 63563 & 69517 \\
\hline Control Function Errors & $\checkmark$ & $\checkmark$ & $\checkmark$ & $\checkmark$ & $\checkmark$ & $\checkmark$ & $\checkmark$ & $\checkmark$ \\
\hline Municipality FE & $\checkmark$ & $\checkmark$ & $\checkmark$ & $\checkmark$ & $\checkmark$ & $\checkmark$ & $\checkmark$ & $\checkmark$ \\
\hline State $\mathrm{X}$ Year FE & $\checkmark$ & $\checkmark$ & $\checkmark$ & $\checkmark$ & $\checkmark$ & $\checkmark$ & $\checkmark$ & $\checkmark$ \\
\hline Controls & $\checkmark$ & $\checkmark$ & $\checkmark$ & $\checkmark$ & $\checkmark$ & $\checkmark$ & $\checkmark$ & $\checkmark$ \\
\hline Control Functions & $\checkmark$ & $\checkmark$ & $\checkmark$ & $\checkmark$ & $\checkmark$ & $\checkmark$ & $\checkmark$ & $\checkmark$ \\
\hline
\end{tabular}

The table presents model specifications, where the dependent variable is the number of firms in (non-)family-intensive/(non-)transportintensive industries as defined in the main text. In Specifications (1) and (2), the number of firms with a 'family-intensity' above and below the median are counted (see definition in the main text), in Specifications (3) and (4), firms with a family-intensity above and below the 75 th percentile of the distribution. Analogously, in Specifications (5) and (6), the dependent variable is the number of firms in industries with a transport-intensity above and below the median (see definition in the main text), in Specifications (7) and (8), firms in industries with a transport-intensity above and below the 75 th percentile are counted. The definition of the spatial lags of the regressors accounts for neigbors within $15 \mathrm{~km}$ distance and weights are based on inverse distance. The definition of the 'Streets' and 'Economic Promotion' regressors corresponds to Section 3, people goods comprise schools, recreations and sports, culture and public education, youth services and public transport and 'other stock' all other categories described in Section 3. Note that the difference in the number of observations across specifications relates to communities, where the dependent variable takes on the value zero for all sample years, so that the respective locality is dropped from the sample. Bootstrapped standard errors in parentheses. ${ }^{* * *},{ }^{* *}$ denote significance at the 10,5 and $1 \%$ level. 


\section{Appendix C: Estimates Baseline Model}

\section{Table C1: Baseline Poisson Regressions}

\begin{tabular}{lccc}
\hline & $\begin{array}{c}\text { Poisson } \\
(1)\end{array}$ & $\begin{array}{c}\text { Poisson } \\
(2)\end{array}$ & $\begin{array}{c}\text { Poisson } \\
(3)\end{array}$ \\
\hline LB Tax & $-0.0010^{* *}$ & & $\begin{array}{c}-0.0009^{*} \\
(0.0005)\end{array}$ \\
PIGS & $(0.0005)$ & $0.0014^{* * *}$ & $\begin{array}{c}0.0013^{* *} \\
(0.0005)\end{array}$ \\
& & $(0.0005)$ & 70653 \\
N & & 70653 & $\checkmark$ \\
Municipality FE & $\checkmark$ & $\checkmark$ & $\checkmark$ \\
State X Year FE & $\checkmark$ & $\checkmark$ & $\checkmark$ \\
Controls & $\checkmark$ & $\checkmark$ & $\checkmark$ \\
Control Functions & $\checkmark$ & $\checkmark$ & \\
\hline Robust standard errors, clustered at the municipality \\
level, in parentheses. $*, * *, * * *$ \\
10, 5 and 1\% lenote significance at the
\end{tabular}

Columns (1) to (3) of Table B1 presents the results for variants of the baseline model in Equation 3. While all specifications absorb time-constant unobserved heterogeneity across jurisdictions and includes a full set of state-year fixed effects and the control variables outlined in Section 3, Specification (1) (Specification (2)) includes the local business tax (the PIGS capital stock) as the sole policy regressor. The point estimate for the local business tax regressor is -0.001 and statistically significant at the 5\% level. Quantitatively, a $10 \%$ increase of the mean local business tax rate is suggested to decrease the expected count of firm foundations by $3.39 \%(33.9 \times$ $0.1 \%){ }^{47}$ Specification (2) yields a positive and significant significant point estimate of 0.0014 for the PIGS regressor. Quantitatively, a 10\% increase of the PIGS Stock increases the number of firm foundations by $0.43 \%(3.044 \times 0.14 \%)$. Combining both the tax rate and our proxy for the total capital stock in one regression (see specification (3)) yields similar results. Hence, using a simple Poisson regression to capture the effects of tax rates and expenditures for PIGS on the number of firm foundations yields significant but moderate point estimates.

\footnotetext{
${ }^{47}$ Note that, as outlined in the main text, the local business tax is measured in local business tax points, with an average of 339 local business tax points in our sample. To arrive at the local business tax in percentage points, the variable is multiplied with a so-called 'Messzahl', which took on the value of $5 \%$ for incorporated businesses and for income of non-incorporated businesses above EUR 48,000 during our sample period.
} 